University of Nebraska - Lincoln

DigitalCommons@University of Nebraska - Lincoln

Historical Research Bulletins of the Nebraska

Agricultural Experiment Station

Extension

$12-1954$

\title{
Influence of Atmospheric and Soil Moisture Conditions on Diurnal Variations in Relative Turgidity of Potato Leaves
}

H. O. Werner

Follow this and additional works at: https://digitalcommons.unl.edu/ardhistrb

Part of the Agriculture Commons, Horticulture Commons, and the Plant Biology Commons

Werner, H. O., "Influence of Atmospheric and Soil Moisture Conditions on Diurnal Variations in Relative Turgidity of Potato Leaves" (1954). Historical Research Bulletins of the Nebraska Agricultural Experiment Station. 185.

https://digitalcommons.unl.edu/ardhistrb/185

This Article is brought to you for free and open access by the Extension at DigitalCommons@University of Nebraska - Lincoln. It has been accepted for inclusion in Historical Research Bulletins of the Nebraska Agricultural Experiment Station by an authorized administrator of DigitalCommons@University of Nebraska - Lincoln. 
UNIVERSITY OF NEBRASKA COLLEGE OF AGRIGULTURE AGRICULTURAL EXPERIMENT STATION

W. V. LAMBERT, Director

M. L. BAKER, Associate Director

Research Bulletin 176

Influence of Atmospheric and Soil Moisture

Conditions on Diurnal Variations in

Relative Turgidity of Potato Leaves

H. O. WERNER

Department of Horticulture

LINCOLN, NEBRASKA

DECEMBER, 1954 

UNIVERSITY OF NEBRASKA COLLEGE OF AGRIGULTURE AGRICULTURAL EXPERIMENT STATION

Influence of Atmospheric and Soil Moisture Conditions on Diurnal Variations in Relative Turgidity of Potato Leaves

H. O. WERnER

Department of Horticulture

LINCOLN, NEBRASKA

DECEMBER, 1954 


\section{CONTENTS}

OBJEGTIVES

EXPERIMENTAL TECHNIQUES

EXPERIMENTAL RESULTS

Influence of Method of Managing Disks on Relative Turgidity Determinations

Similarities of paired disks

Dependability of fresh weight for calculating weight of water in disks.

Surface moisture on leaves

Temperature of water used for floating disks

Light intensity at surface of disks

Relative humidity above floating disks 12

Leaf appearance at sampling time

Evaporation from black atmometers during one hour before sampling

Effect of Environmental Conditions upon Leaf Turgidity 16

Observations at Scotts Bluff in 1951 17

Observations at Lincoln in 1952.

DISCUSSION

SUMMARY 36

BIBLIOGRAPHY 


\title{
Influence of Atmospheric and Soil Moisture Conditions on Diurnal Variations in Relative Turgidity of Potato Leaves
}

\author{
H. O. WERNER ${ }^{1}$
}

$\mathrm{G}$ REAT VARIATIONS in morphological characteristics and in ability to survive heat and drought are observable among the hundreds of varieties and thousands of clones used in modern potato breeding programs. Very little is known about the relationship of these morphological types to heat or drought endurance or to relative metabolic efficiency of the plants. Consequently, it is still necessary to depend exclusively on empirical field tests replicated in various localities and seasons to determine the probable adaptability of a clonal selection. Many techniques for satisfactorily screening potato seedling populations for resistance to specific diseases are in use. Techniques of similar dependability for evaluating the physiological significance of various morphological types might enable the potato breeder to select those types most suitable for specific purposes or environments.

The determination of the relative turgidity of leaves as used by Weatherley $(1950,1951)$ appears to be a satisfactory, relatively simple, and fairly rapid method of evaluating the physiological response and status of plants that may differ as to age, culture, variety, etc. A knowledge of the relative turgidity of leaves is not only valuable for a better understanding of water relationships but may also be a fairly dependable indicator of general physiological activity because of the high correlation between leaf turgidity and photosynthetic activity. Weatherley's method appears more suitable for ascertaining the response of plants to conditions affecting the water content of the leaf than many other methods. It therefore seemed desirable to determine the suitability of this method for exploring some of the water relations of potato plants as influenced by variety difference and environmental conditions.

The relative turgidity (R.T.) of leaves (of a given variety or treatment, etc.) is calculated as the percentage that the weight of the water in one set of disks at cutting time (W.a) is of the weight of the water in another set of simultaneously cut disks (W.b) that have attained the maximum turgidity of which the leaf disks are capable.

${ }^{1}$ H. O. Werner is Horticulturist, Nebraska Agricultural Experiment Station. The data upon which this publication is based were acquired by Joan M. Wallace working under the general direction of the author. 


\section{OBJECTIVES}

The experimental work reported herein was planned to determine:

1. The extent and nature of the changes of the relative turgidity of leaves of the potato plant during the diurnal cycle.

2. The extent to which R.T. of potato leaves is influenced by atmospheric conditions, soil moisture, variety and age of plants.

3. The extent to which visible evidence of water shortage in leaves is indicative of water loss from them as revealed by R.T. and the extent to which this relationship varies with different varieties.

4. The nature of the relationships between morphological characteristics of leaves and stems and the R.T. characteristics of the leaves of various potato plants.

\section{EXPERIMENTAL TECHNIQUES}

The procedures followed in determining the relative turgidity of potato leaves in 1951 and 1952 were based on the experience of Weatherley and on preliminary tests conducted with potatoes at Alliance, Nebraska in $1950 .{ }^{2}$ The methods used were as follows:

Paired sets of disks were cut at the same time from 30 leaves with sharp cork borers (14.2 mm. in diameter). Immediately after cutting, the disks were transferred to weighing bottles and the fresh or field weights were obtained promptly in the laboratory (F.W.a and F.W.b). Then disks of one sample were dried in an oven at $95^{\circ}-100^{\circ} \mathrm{C}$. for 24 hours (D.W.a) and the disks of the other sample were floated on water. For convenience they were floated for 24 hours-Weatherley (1950) having found little difference in cotton leaf disks floated 12 or 24 hours. This was done in a residence cellar, where temperatures ranged between $68^{\circ}$ and $72^{\circ} \mathrm{F}$. An overhead electric lamp provided continuous light of 40 foot-candles at the surfaces of the dishes.

Relative turgidity values were calculated as the percentage that the water in sample a (W.a) was of the water in sample b after floating (W.b.). However, because of the unavoidable variation in the fresh weights of the two sets of disks, this value was adjusted by using the ratio of F.W.b/F.W.a as shown in the formula on page 5. This adjustment is based on the assumption (verified later) that variations in water weights of two samples are practically identical to the variations in fresh weight of the samples.

The method can be visualized quite readily from the following graphic outline (as essentially designed by Weatherley);

\footnotetext{
${ }^{2}$ This phase was conducted by W. L. Jewel.
} 


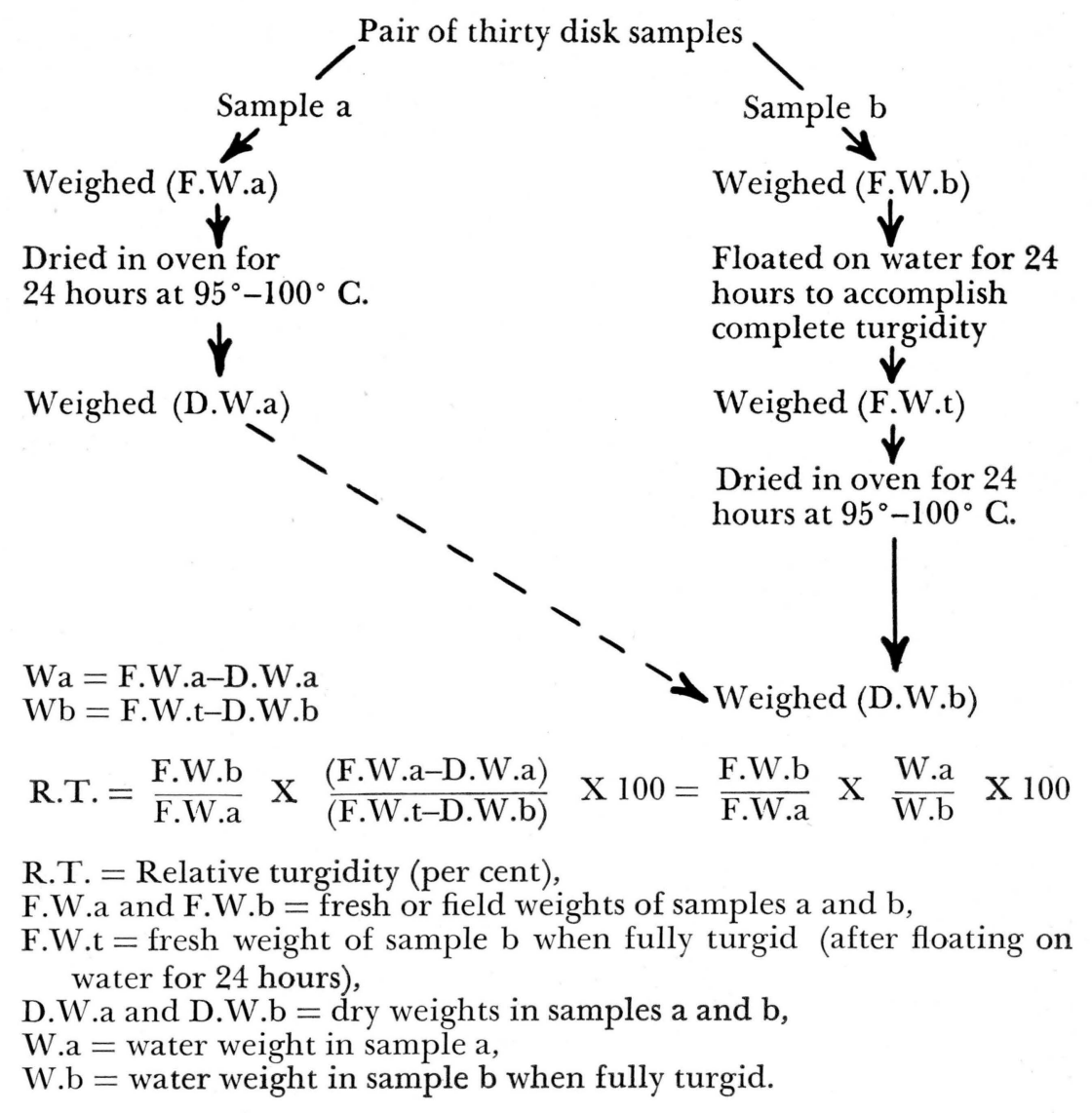

By fastening two cork borers together at an angle of about 30 degrees, the two sets of disks could be cut as nearly simultaneously as possible by cutting a disk from one side of a leaflet with one borer and then from the other side with the other borer. Because of possible differences between the two sides of the leaflets the same number of disks were cut from each of the sides by alternately cutting disks with each borer from the abaxial side of one leaflet and the adaxial side of the other. At each sampling time disks were cut from the most recently fully developed leaves located on the sunny side of the plants (Stone 1933). Only one pair of disks was cut from any one plant at any one sampling period. At all sampling times on the same day or in the same series the disks were taken from the same plants. On most days plants of three to six treatments or varieties were sampled during each of three to seven periods from sunrise until late afternoon or early evening. From 6 to 15 minutes was required to cut the two 30 disk samples of a variety or treatment; hence, most samples taken at 
one time were obtained within a 30 - to 60-minute interval. With only one person working an unavoidable error occurred because of this lag in time. During each sampling period the consequences of this error were diminished by randomizing the order of sampling. With some aspects of these studies the lack of simultaneous sampling was of no consequence but for some comparisons the R.T. values were adjusted to standard times of the day by utilizing the ratio of R.T. to the rate of evaporation from black atmometers.

When dew occurred on leaves during the early morning hours it was removed from the disks with absorbent tissue before determining their field weight-a practice based on method studies reported herein.

On sampling days water losses from two black atmometers, located just above the tops of the potato plants, were read before procuring each pair of samples and immediately after the last sample of a series was obtained. The readings from these are referred to as B.A.L., "black atmometer loss." Wet and dry bulb thermometer readings were always obtained in the field at the beginning and end of each sampling period and several other times on many days. Continuous temperature records were obtained from thermographs located in ventilated shelters in the field at the level of the plants.

The results from most of the 1950 work on dry land at Alliance was useful in developing procedures. For most of the work in 1951, plants grown for an irrigation experiment at the Scotts Bluff Experiment Station were used. These plants emerged above the soil during the first week of July. Irrigation practice was governed by the findings with a series of soil moisture tensiometers, electrical conductivity readings of buried porous blocks, and by oven drying of soil moisture samples. ${ }^{3}$

Leaf samples were taken between July 25 and August 25 from plants of three irrigation treatments, viz: (number 1$)^{4}$-abundant soil moisture (close to field carrying capacity by frequent irrigation); (number 6)-intermediate or variable soil moisture (irrigating half as frequently by omitting the second and fourth irrigations); and (number 11)-very low soil moisture (no irrigation until the fifth irrigation).

The majority of the samples were obtained from Progress plants, but Triumph plants were sampled on enough days to provide preliminary evidence of the nature of varietal differences.

In June 1952 another group of samples were acquired at Lincoln from plants of six varieties planted in April 1952. These plants made luxurious growth during May, but were greatly retarded by the very hot, dry weather in June.

${ }^{3}$ These data were acquired by Orlando Howe, U.S.D.A. Irrigation Engineer, as part of an irrigation study.

${ }^{4}$ Numbered treatments are those that were used by Mr. Howe in his experiment, the plants of which were utilized for this project. The letters $P$ and $T$ used as prefixes to treatment numbers indicate the varieties Progress and Triumph. 


\section{EXPERIMENTAL RESULTS}

\section{Influence of Method of Managing Disks on Relative Turgidity Determinations}

Because of some concern that certain sampling or laboratory practices might influence the amount of water absorbed by the disks, several supplementary method studies were conducted in the field in 1950 and 1951 and at Lincoln throughout the winter and spring.

Because relative turgidity values are calculated from the amount of water absorbed by one set of the paired disks during floating, it was advisable to determine the possible influence of the various environmental aspects associated with the floating procedure upon the amount of water absorbed by the disks and the degree of similarity of the weight of paired disk samples. Variables that were considered likely to have some influence on water absorption by the floating disks were: surface moisture on leaves at sampling time, and temperature and light intensity or relative humidity of the air over leaf disks during floating. The results of some simple tests conducted before or during the course of the major studies either governed the methods used or became useful in evaluating the data acquired by methods which necessarily were a compromise between ideal practice and physically feasible procedures.

Similarities of paired disks. The correlation coefficient of fresh (or field) weights of the a and $\mathrm{b}$ samples of 73 pairs of disks from leaves of the Progress variety procured near Alliance in 1950 was $r=0.887$. The mean of F.W.b/F.W.a ratios of these disks was 1.022.

Dependability of fresh weight for calculating weight of water in disks. The dependability of the fresh weight of the disks for calculating the weight of the water they contained was confirmed by the high correlation coefficients between F.W.a and W.a, these having been:

In $1950-\mathrm{r}=0.987$ with 73 sets of Progress disks

In $1951-\mathrm{r}=0.9714$ with 139 sets of Progress disks

In $1951-\mathrm{r}=0.9596$ with 57 sets of Triumph disks

Apparently changes in dry matter content or environment did not have much influence on the ratio of F.W.a to W.a for, although disks of these populations were obtained under a great variety of conditions with regard to time of day, climate, age of plants, etc., the correlation always remained high.

Surface moisture on leaves. The mean R.T. of four sets of disks from dew-covered leaves weighed and floated without removing the free surface water was calculated as 116.6 per cent. However, even though saturated with dew, the leaves did not attain 100 per cent R.T. because the mean R.T. of four other sets of disks that were cut after 
TABLE 1. Relation of time of removing surface moisture from leaves of disks in the field vs. in the laboratory to the relative turgidity of leaf disks as calculated from the actual data and data adjusted ${ }^{1}$ to probable values at 7 a.m.

\begin{tabular}{l|c|c}
\hline \hline \multicolumn{1}{c}{$\begin{array}{c}\text { Method of removing } \\
\text { surface moisture }\end{array}$} & $\begin{array}{c}\text { Mean of 4 samples } \\
\text { Relative } \\
\text { turgidity- } \\
\text { from } \\
\text { actual data }\end{array}$ & $\begin{array}{c}\text { Relative } \\
\text { turgidity- } \\
\text { from data } \\
\text { adjusted to } \\
\text { a.m. values }\end{array}$ \\
\hline Surface moisture removed in the field & per cent & per cent \\
Moisture removed from discs in the laboratory & 96.09 & 95.92 \\
\hline Difference & 95.21 & 95.50 \\
\hline F. as calc. & 0.88 & 0.42 \\
F. for sign @ $5 \%$ & .76 & 0.97 \\
\hline
\end{tabular}

1 Adjusted by using rate of change in per cent of R.T. per mean rate of change in water loss from black atmometers as cc. per hour.

the free surface moisture was removed with absorbent tissue was only 96.09 per cent (table 1). With still another set of disks cut wet and quickly freed of surface moisture (with absorbent tissue) before weighing and floating, the mean calculated R.T. was 95.21 per cent. Although taken in randomized order, there were apparently too few sets of disks to avoid bias of the mean by the changes that took place within the time of the sampling periods. However when the means of R.T. for all sets were adjusted to the arbitrarily chosen time of 7 a.m. ${ }^{5}$ the two methods of removing surface moisture gave practically the same R.T. means-i.e., 95.92 per cent for field and 95.50 per cent for laboratory removal of surface moisture.

Temperature of water used for floating disks. The influence of the temperature of water used for floating disks, upon the amount of water absorbed and thereby on their calculated initial R.T., was determined by floating five sets of leaf disks at each of four temperatures-but under uniform light, i.e., 75 to 80 foot-candles at the top surfaces of the disks. With disks cut from greenhouse plants in December and April 1951-52, water absorption increased as the temperature increased and was greater with the more xerophitic April leaves than with the thin relatively succulent December leaves (figure 1). Consequently, calculated initial R.T. values of the disks decreased as the temperature of the water increased (figure 2).

${ }^{5}$ Adjusted to uniform time of day by using the rate of change in R.T. per minute and the existing rate of evaporation from black atmometers-a method based on findings reported later in this bulletin. 


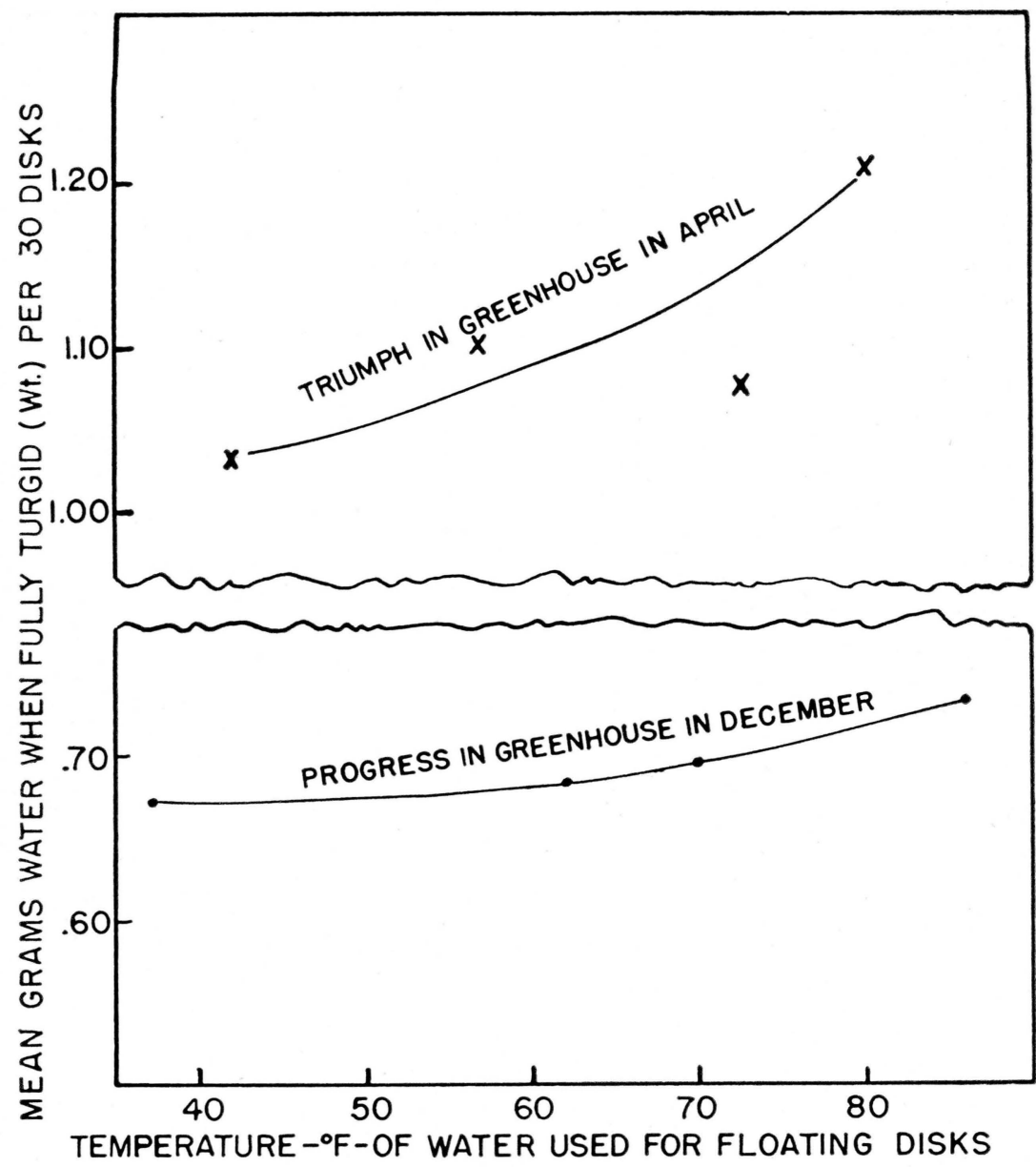

Figure 1.-Mean grams of water absorbed by 30 potato leaf disks when floated at various temperatures. Values depicted for each temperature in December (1951) were based on four sets and in April (1952) on five sets of disks. (Illumination at surface of water was 75-80 foot-candles with all sets.)

Light intensity at surface of disks. For determining the influence of light intensity during floating, a series ranging from 0 to 130 footcandles at the surfaces of the disks was established by placing the dishes of water at distances from a light where the desired intensities were determined with a precision light meter. Unfortunately, it was not possible under the circumstances of these tests to maintain the disks of all light treatments at a uniform temperature even though a stream of air from an electric fan was directed below the lights to 


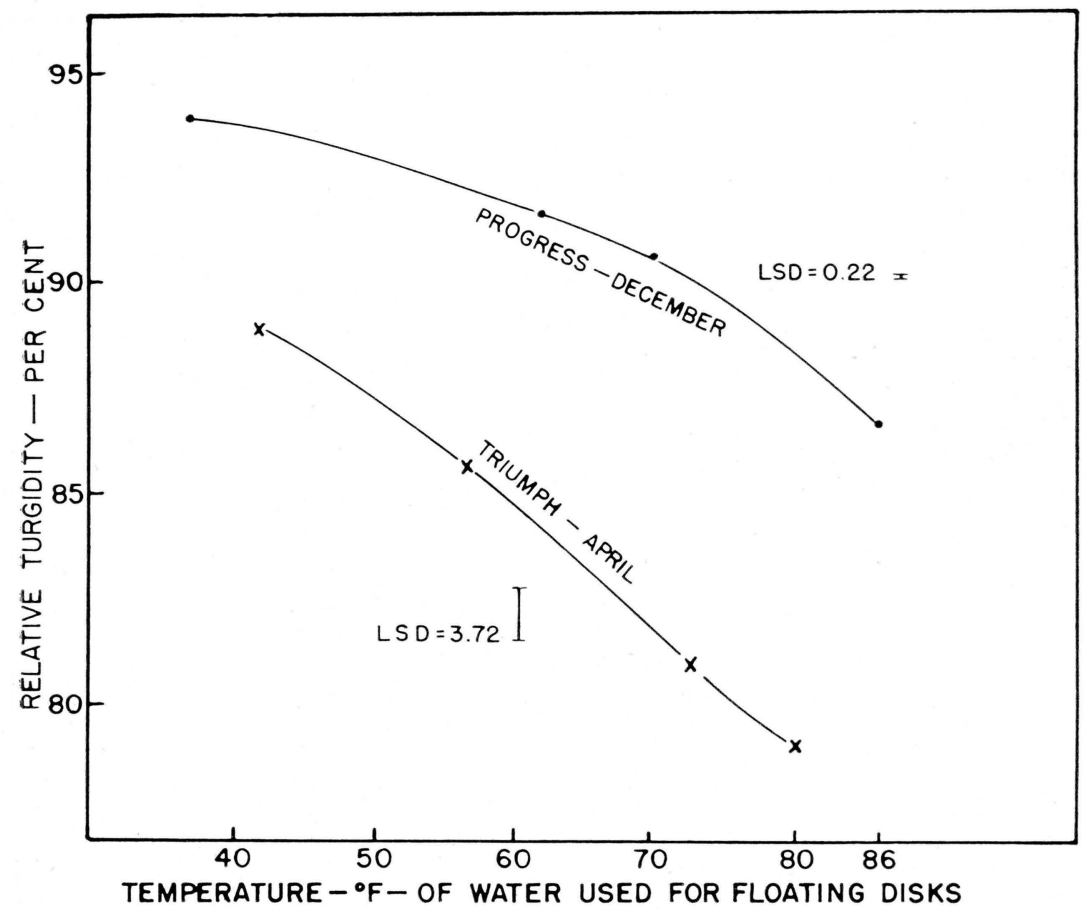

Figure 2.-Mean initial relative turgidity values calculated for leaf disks floated on water at different temperatures. (Based on the same disks utilized for figure 1.)

TABLE 2. Relation of light intensity while floating to calculated initial relative turgidity of disks. (Parenthetical values are mean temperatures $\left({ }^{\circ} \mathrm{F}\right.$.) of water on which disks were floated.)

\begin{tabular}{|c|c|c|c|}
\hline \multicolumn{4}{|c|}{ Variety and sampling time } \\
\hline \multicolumn{2}{|c|}{$\begin{array}{c}\text { Progress } \\
\text { December 18, } 1951\end{array}$} & \multicolumn{2}{|c|}{$\begin{array}{c}\text { Triumph } \\
\text { April, } 1952\end{array}$} \\
\hline Light & $\begin{array}{c}\text { Mean relative } \\
\text { turgidity }^{1}\end{array}$ & Light & $\begin{array}{c}\text { Mean relative } \\
\text { turgidity }^{1}\end{array}$ \\
\hline f.c. & per cent & f.c. & per cent \\
\hline 120 & $90.98\left(68^{\circ} \mathbf{F}\right)$ & 130 & $90.72\left(74^{\circ} \mathrm{F}.\right)$ \\
\hline 80 & 90.24 & 83 & $88.73\left(73^{\circ} \mathrm{F}.\right)$ \\
\hline 60 & $91.72\left(67^{\circ} \mathrm{F}.\right)$ & 50 & $91.47(71 \circ \mathrm{F})$. \\
\hline 18 & $90.97 \quad\left(62^{\circ}\right.$ F. $)$ & 22 & $93.31\left(69.5^{\circ} \mathrm{F}.\right)$ \\
\hline 0 & $91.60\left(64^{\circ}\right.$ F. $)$ & 0 & $91.79\left(69.0^{\circ} \mathrm{F}.\right)$ \\
\hline F. as calc. & 0.9 & & 14.77 \\
\hline F. at $5 \%$ & 3.01 & & 2.87 \\
\hline $1 \%$ & 4.77 & & 4.43 \\
\hline L.S.D. & & & $2.15 \%$ \\
\hline
\end{tabular}

1 All means based on five paired sets of disks. 
carry heat away from the floating disks. (The extent of the temperature deviations of the water can be learned from the values presented parenthetically with the various R.T. means shown in table 2).

The dry weights of floating disks increased with light intensity as shown by the ascending D.W.b/D.W.a line in figure 3. Loss and gain of dry matter of the disks appeared to be balanced at about 40 footcandles of light. Even though the water content of the disks changed greatly, the calculated initial R.T. values were altered very little or not at all by the differences in light. This and several other determinations, when lights were accidentally turned off without any untoward results, lead to the conclusion that although light altered accumulated dry matter greatly, it tended to alter R.T. values very slightly or not at all. At no time did any disks become injected (water soaked) owing to darkness during the floating time.

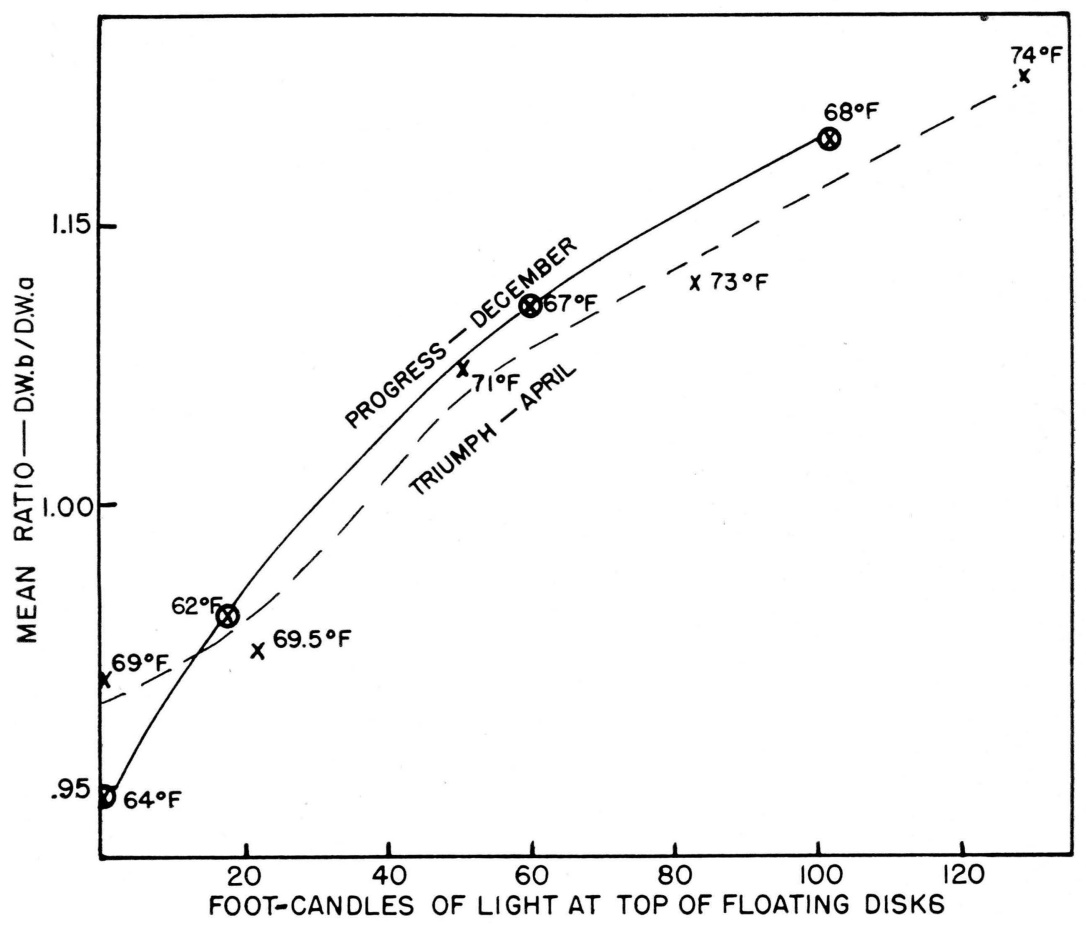

Figure 3.-Differences in increase in dry weight of two groups of potato leaf disks floated at various light intensities reported as D.W.b/D.W.a ratios. Each point shown is the mean of four sets of disks floated at each light intensity. Mean temperatures of floatation water are reported adjacent to the symbol for the value of each light treatment. 
Relative humidity above floating disks. The relative humidity of the atmosphere over the floating disks was varied by covering some dishes with loosely fitting glass lids that provided a clearance of about $1 \mathrm{~cm}$. above the water. Sets of disks in covered dishes and check lots in open dishes were floated in darkness, and others-both covered and open-were floated under 40 foot-candles of light. The condensation of moisture on the lower sides of the lids indicating that the atmosphere under the covered dishes was saturated.

The mean of initial R.T. values calculated from eight sets of the disks floated at high humidity (covered dishes) was 1.65 per cent lower than that of the eight sets at the low humidity (open dishes) (table 3A). The differences in R.T. means were relatively the same in both light and darkness. The reduced transpiration of disks in the saturated atmosphere of the covered sets may have permitted those disks to absorb or at least to retain more water than those in the open dishes, thereby bringing about a lower calculated R.T. for the leaves at disk cutting time. Undoubtedly the slightly higher water temperature in the covered dishes and in those under the lights contributed to the lowering of these calculated R.T. values. The plausibility of the temperature influence is shown by the gradual reduction in calculated R.T. as the temperature increased, as follows:

Treatment: Dark-open $>$ light-open $>$ dark-covered $>$ light-covered

Mean temperature ${ }^{\circ}$ F.: $79.7<80.4<81.0<81.9$

Mean R.T.: $88.82 \%>88.09 \%>87.30 \%>86.30 \%$

TABLE 3. Mean initial relative turgidity values calculated from disks floated in covered and open dishes when held in light (40 f.c.) and darkness during the floating period. (Pawnee potato leaves-June, 1952. Four sets of disks for each light and humidity treatment.) (Parenthetical values are means of water temperature during floating periods.)

\begin{tabular}{|c|c|c|c|}
\hline \multirow[b]{2}{*}{$\begin{array}{l}\text { Light } \\
\text { treatment }\end{array}$} & \multicolumn{2}{|c|}{ Surface control } & \multirow{2}{*}{$\begin{array}{l}\text { Means of } \\
\text { light } \\
\text { treatments }\end{array}$} \\
\hline & $\begin{array}{c}\text { Open } \\
\text { (Low humidity) }\end{array}$ & $\begin{array}{c}\text { Covered } \\
\text { (High humidity) }\end{array}$ & \\
\hline
\end{tabular}

(A.) R.T. values at original temperatures.

\begin{tabular}{lllc}
\hline Light & $88.09\left(80.4^{\circ} \mathrm{F}.\right)$ & $86.30\left(81.9^{\circ} \mathrm{F}.\right)$ & $\begin{array}{c}\text { per cent } \\
87.20\left(81.15^{\circ} \mathrm{F} .\right)\end{array}$ \\
Darkness & $88.82\left(79.7^{\circ} \mathrm{F}.\right)$ & $87.30\left(81.0^{\circ} \mathrm{F}.\right)$ & $88.05\left(80.35^{\circ} \mathrm{F}.\right)$ \\
\hline Means of 8 sets in & & & \\
"covering" series & $88.45\left(80.1^{\circ} \mathrm{F}.\right)$ & $86.80\left(81.4^{\circ} \mathrm{F}.\right)$ & $87.63\left(80.75^{\circ} \mathrm{F}.\right)$ \\
\hline
\end{tabular}

Light X surface: F. as calc. 6.68; F. @ $1 \% 6.99$.

L.S.D. (mean of 4 sets) $1.55 \%$; (mean of 8 sets) $0.75 \%$.

(B.) R.T. values adjusted to $80.75^{\circ} \mathrm{F}$.

\begin{tabular}{llll}
\hline Light & 88.01 & 86.59 & 87.32 \\
Darkness & 88.57 & 87.36 & 88.12 \\
\hline Means of 8 sets in & & & \\
"covering" series & 88.29 & 86.97 & 87.63 \\
\hline
\end{tabular}




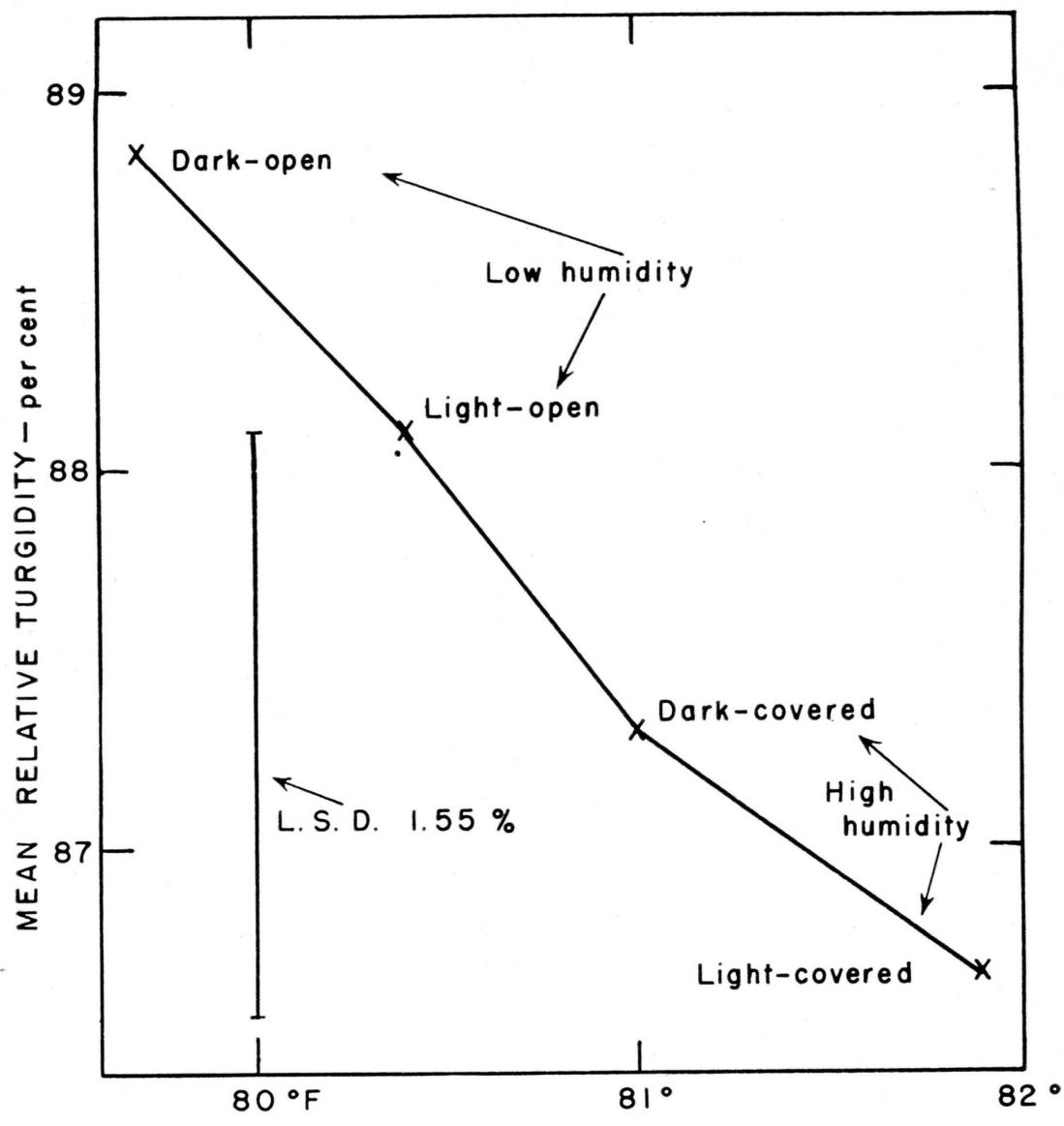

TEMPERATURE OF WATER DURING FLOATING

FIGURE 4.-Relative turgidity of disks floated in open and covered dishes (to provide low and high relative humidity in atmosphere over disks) with 40 foot-candles light intensity, and in darkness plotted against the temperature of the water used for floating.

The probability of this temperature influence is shown by the sharp decline in R.T. when the values for various treatments are plotted as shown in figure 4 . However, when adjusting all R.T. values to the mean temperature of the experiment by reducing the R.T. 0.25 per cent for each $1^{\circ} \mathrm{F}$. increase in temperature (as found in the temperature series reported in figure 2), the R.T. values were distorted only 0.55 per cent by the $2.2^{\circ} \mathrm{F}$. extreme difference between means of temperatures of various treatments (table $3 \mathrm{~B}$ ). When all R.T. values are corrected to the mean temperature of $80.75^{\circ} \mathrm{F}$., the mean R.T. increase for eight sets at low humidity was 1.32 per cent and that for eight sets in darkness was only 0.80 per cent. 
Leaf appearance at sampling time. In order to attain one of the major practical objectives, i.e., to determine the relation between leaf appearance and internal water content of potato leaves, the appearance of the leaves of each variety or treatment when disk sampling began was evaluated on the following basis: ${ }^{6}$

0 . Leaves very turgid, with both leaf surfaces wet.

1. Leaves very turgid, with lower leaf surface moist.

2. Leaves very turgid, with beads of moisture among leaf hairs on lower surfaces.

3. Leaves very turgid, with surfaces apparently dry.

4. Leaves lacking full turgor and feeling slightly soft.

5. Leaves distinctly soft, terminal leaves drooping slightly.

6. Terminal leaflet and adjacent first or second pairs of leaflets drooping slightly.

7. Terminal leaflet drooping extensively and basal leaflets turgid but soft.

8. Leaflets of apical half of leaf drooping severely, basal leaves drooping slightly.

9. All but basal pair of leaflets showing maximum drooping.

10. All leaflets showing maximum drooping-more than one fourth of leaves on plant drooping.

11. More than half of leaves on plant drooping.

12. All leaves of plant showing some drooping.

Very high correlation coefficients existed between R.T. and the estimated leaf appearance of large numbers of sets of Triumph and Progress leaves sampled in 1951 (figure 5 and table 4). Progress leaves suffered more desiccation for a given change in leaf appearance than did Triumph leaves. This is shown by the steeper regression lines in figure 5, and the average reduction of 5.53 per cent in R.T. for each

TABLE 4. Mean relative turgidity and mean estimated leaf condition of numerous samples of Progress and Triumph leaves in 1951.

\begin{tabular}{|c|c|c|c|c|c|c|}
\hline Variety & $\begin{array}{l}\text { Number of } \\
\text { pairs of } \\
\text { leaf samples } \\
(\mathrm{n} .)\end{array}$ & $\begin{array}{c}\text { Mean } \\
\text { evidence } \\
\text { of leaf } \\
\text { dncinfinn } \\
\text { (E.L.D.) }{ }^{1}\end{array}$ & $\begin{array}{l}\text { Mean } \\
\text { relative } \\
\text { turgidity } \\
(\mathrm{R} . \mathrm{T} .)\end{array}$ & $\begin{array}{c}\text { Corr. } \\
\text { coef. } \\
\text { (r.) }\end{array}$ & $\begin{array}{l}\text { Change } \\
\text { in R.T. } \\
\text { per unit } \\
\text { E.L.D. }\end{array}$ & $\begin{array}{l}\text { Units } \\
\text { E.L.D. } \\
\text { per } \\
1 \% \text { R.T. }\end{array}$ \\
\hline & \multicolumn{4}{|c|}{$\mathrm{pcr}$ cent } & \multicolumn{2}{|l|}{ per cent } \\
\hline Progress & $35^{2}$ & 3.89 & 87.2 & .641 & 5.53 & .161 \\
\hline Triumph & $35^{2}$ & 4.29 & 83.8 & .877 & 3.60 & .278 \\
\hline Progress & $103^{3}$ & 4.18 & 85.0 & .816 & 4.48 & .223 \\
\hline Triumph & $41^{3}$ & 4.12 & 84.6 & .874 & 2.59 & .386 \\
\hline
\end{tabular}

${ }^{1}$ E.L.D.= "Evidence of leaf desiccation" based on values shown on page 14 .

2 Includes only the 35 pairs of samples taken when both varieties were available for each of the sampling periods.

3 The larger groups of each variety included all sets available of each variety.

'These values are referred as E.L.D., i.e., "evidence of leaf desiccation." 


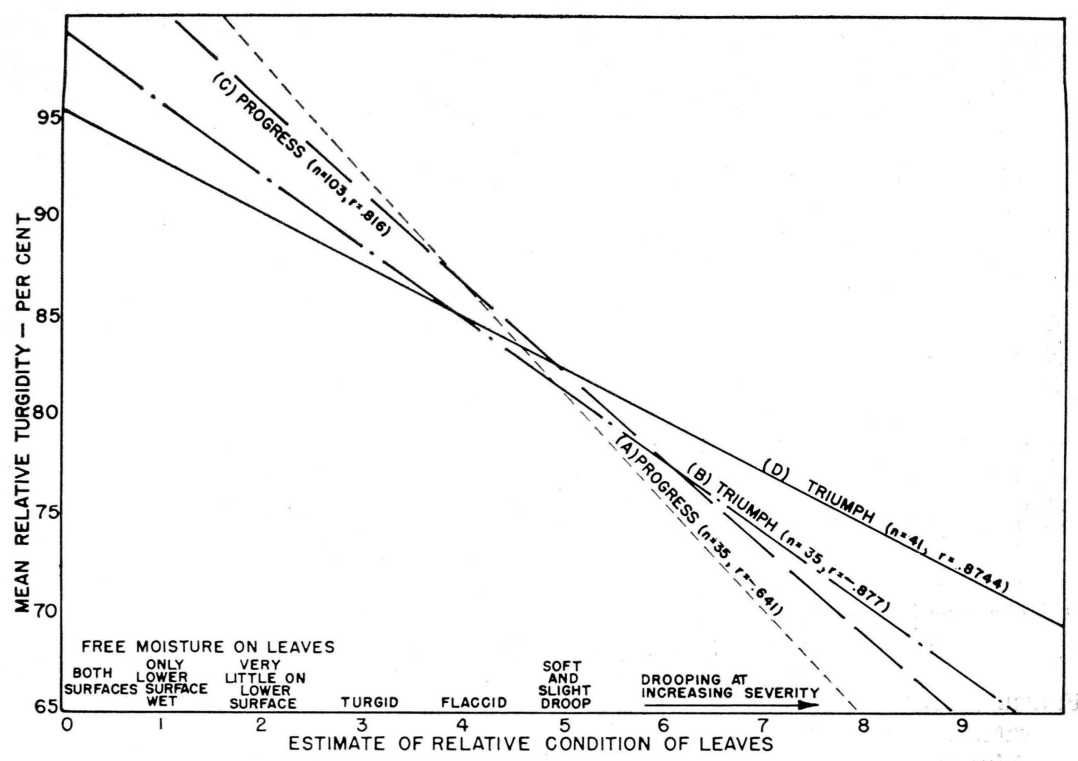

Figure 5.-Reduction in calculated initial relative turgidity of two groups of Triumph and Progress leaves (leaves changed from full turgidity to full drooping, see table 4).

unit increase in leaf wilting compared with only 3.60 per cent for Triumph leaves sampled at the same time (means of 35 samples in table 4). Thus for each drop of 1 per cent in R.T. the mean increase in severity of leaf desiccation appearance was .161 units with Progress and .278 with Triumph. When the leaves appeared to be turgid the R.T. values were higher with Progress than with Triumph. The R.T. of both varieties was the same ( 82.5 per cent) when first visible but slight drooping of leaves occurred (E.L.D. of 5). As wilting increased, Progress leaves suffered more desiccation than Triumph leaves of the same appearance.

These data might indicate that more favorable conditions are required for Triumph than for Progress leaves to approach 100 per cent turgidity. This might also indicate that in order to avoid retardation in growth of plants and tubers, it is more important with Progress than with Triumph to begin irrigation before the plants have wilted seriously.

Evaporation from black atmometers during one hour before sampling. The correlation between R.T. and water loss from a black atmometer (B.A.L.) during one hour prior to sampling was found to be $r=0.976$ with Progress and $r=0.961$ with Triumph leaves (23 sets each) in 1952 (figure 6). More discussion of this relationship occurs in the later portions of this bulletin. 


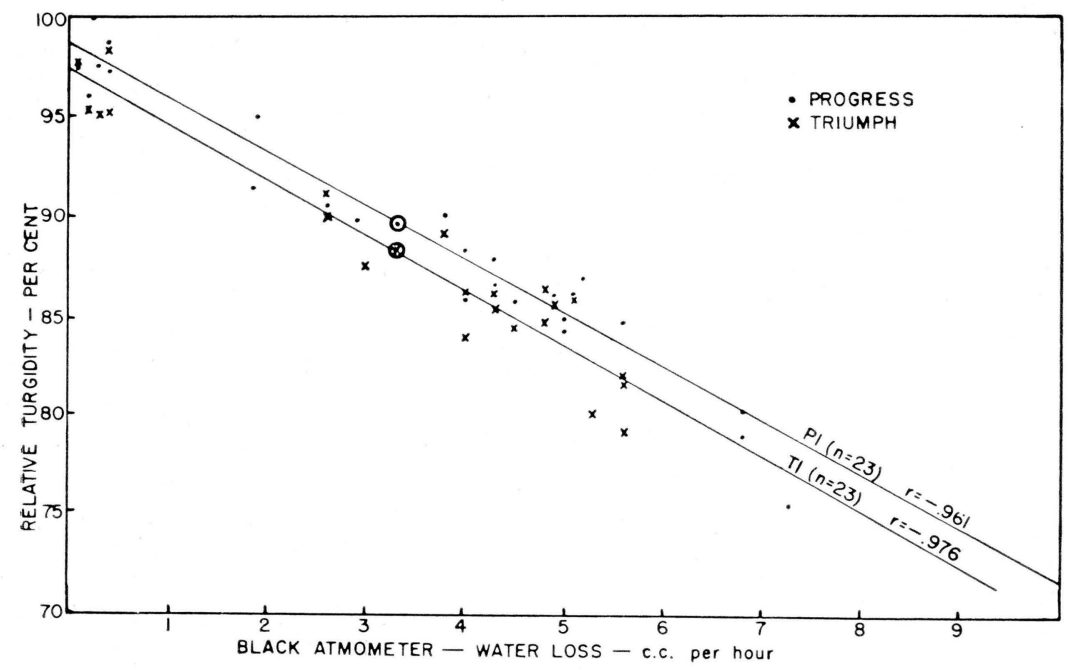

Figure 6.-Correlation between percentage relative turgidity and cubic centimeters of water lost per hour from spherical black atmometers (B.A.L.) with 23 sets of Triumph and Progress leaves at identical sampling periods. (All B.A.L. values are means from two atmometers located in the field just above the tops of the potato plants.)

It is desirable to adjust R.T. values taken throughout a 30 - to 60minute sampling period to a standard time for comparative and analytical purposes. An adjustment of that type can be made for any given number of minutes, on the basis of the R.T./cc. B.A.L. ratios. ${ }^{7}$

\section{Effect of Environmental Conditions upon Leaf Turgidity}

The effect of several environmental components on relative turgidity of potato leaves was established with the sets of leaf disks obtained throughout each day during a number of groups of days in August 1951 at the Scotts Bluff Experiment Station and in June 1952 at Lincoln. The environmental conditions under which these plants were grown or the variables established within each group were as follows:

A. Western Nebraska, August 1951, relatively bright warm days with a great diurnal range in temperatures:

1. Progress variety with three irrigation treatments, August 1 to 4 ;

2. Progress with three and Triumph with two irrigation treatments, August 8 to 11;

3. Progress and Triumph plants with optimum irrigation, August 23 to 25 .

${ }^{7}$ Mean cc. water loss per hour from one spherical black atmometer. 
B. Eastern Nebraska (Lincoln), June 1952:

4. Six varieties during a period of very hot weather with soil moisture relatively low, June 9 to 11 ;

5. Six varieties, constantly decreasing soil moisture during the close of a protracted period of clear, hot, dry weather which changed abruptly to cloudy, wet and relatively cool weather, June 16 to 20 .

Observations at Scotts Bluff in 1951. The weather during the test periods in August 1951 was typical for the month. Temperature and evaporation were highest for the period of series 1 and lowest for series 3 (figure 7). Most of the moisture used by the frequently irrigated plants $(\mathrm{Pl})^{8}$ was obtained from the top 30 inches (figure 8). At each irrigation the soil moisture throughout the root zone was replenished to the field carrying capacity. After irrigation the tensiometer readings for a depth of 6 inches were usually 50 to 75 millimeters

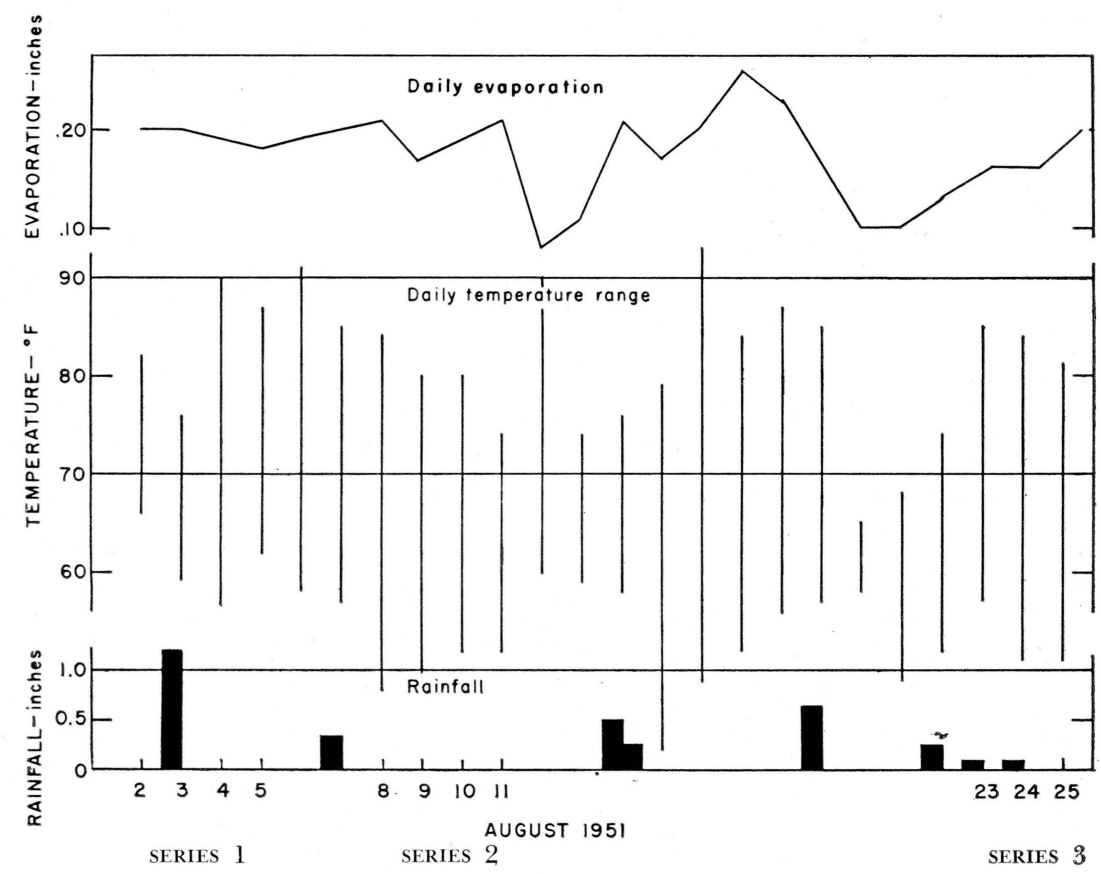

Figure 7.-Evaporation, maximum and minimum temperature, and rainfall at the Scotts Bluff Experiment Station on each day in August 1951.

${ }^{8}$ Letters refer to varieties and numbers to irrigation treatments, e.g., P1=Progress, irrigation treatment $1 ; \mathrm{T} 6=$ Triumph, irrigation treatment 6 . See also footnote 4 , page 6. 


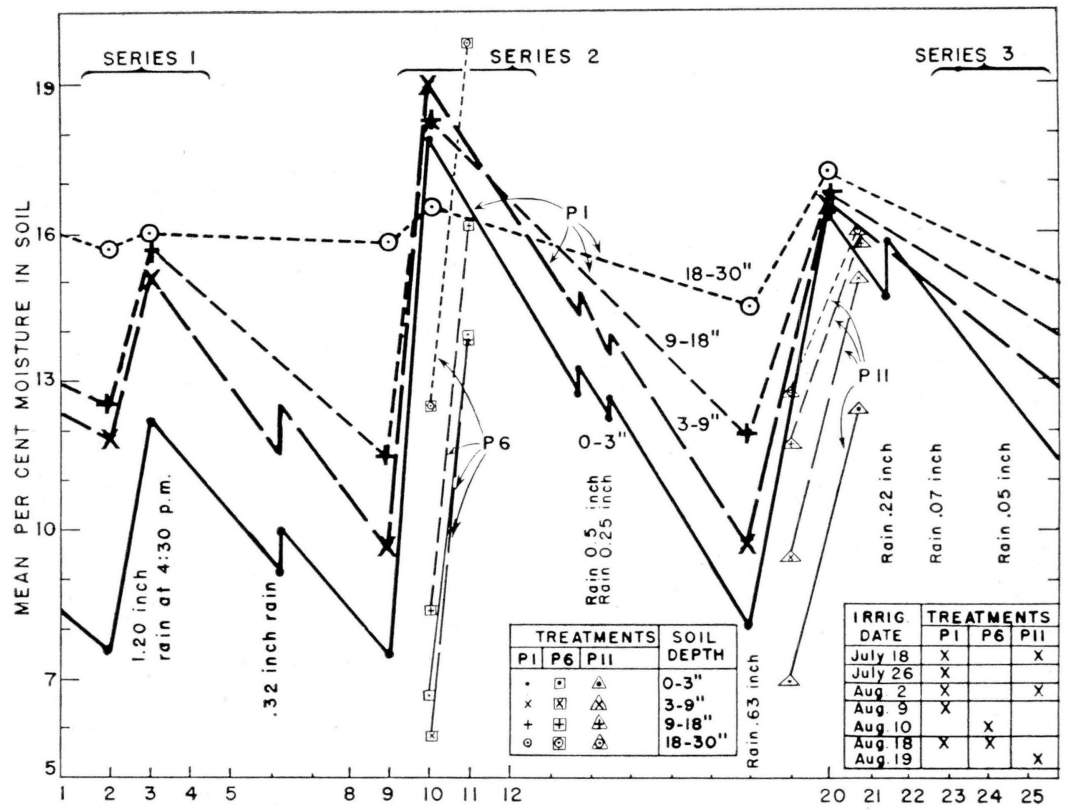

FIGURE 8.-Percentage of soil moisture at various soil levels in plots of Progress potatoes at the Scotts Bluff Experiment Station throughout the time of the relative turgidity studies in August 1951:

(a) In the frequently irrigated plats (P1) throughout the entire period when irrigated third time August 2, fourth time August 9, fifth time August 18.

(b) In the delayed irrigated plats (P6) just before and after the first irrigation of those plats (August 10), at the time of the fourth irrigation with P1.

(c) In the infrequently irrigated plats (P11) before and after the third irrigation of those plats (August 19), at the time of the fifth irrigation with P1.

of mercury (figure 9). When they attained about $300 \mathrm{~mm}$. at the $3-9$ inch depth the soil moisture was close to the wilting point-approximately 7 per cent in these soils. At these times the soil moisture in 9-18 inch and 18-30 inch levels was reduced to approximately 9.5 and 12.5 per cent respectively (figure 8). This was only about 25 and 50 per cent respectively of the available water capacity at these depths. At this stage the plants were drooping slightly for several hours in the middle of the day when temperatures were about $85^{\circ} \mathrm{F}$. or higher, but they recovered quickly during the late afternoon. With both varieties, growth of tops was as luxuriant as can be obtained in the locality with the most favorable moisture conditions.

With plants subjected to droughty conditions by withholding irrigation water until August 10 (with treatment P6-the fourth irrigation to the frequently irrigated plats) the soil moisture content in the top 9 inches just prior to irrigation was distinctly below the wilting point and that of the 9-18 inch level was very close to it. 
Half of the available water had been removed from the 18-30 inch depth and a small amount had been extracted from the 30-42 inch depth (figure 8). Irrigation replenished the moisture throughout various depths almost to the field carrying capacity. Prior to irrigation many of the leaves had burned severely or dropped off, reducing the foliage area by half or more (compared with the irrigated plants). Even so, the leaves were drooping on mild days and for 4 to 7 hours on hot days. After irrigation recovery was fairly complete within a day or two, as shown by midday wilting, but resumption of vegetative growth was slower.

After this first irrigation and after rains of 0.5 inch or more the tensiometer readings of the top 6 inches were of little value for indicating the water deficit within these plants (figure 9). Available water was removed quickly and almost completely from the upper layers of soil even though much water was available at slightly greater depths (figure 8).

Intermittent irrigation (P11-half as frequently as with frequent irrigation-P1) brought about slightly reduced plant growth and somewhat more severe midday wilting during the extended periods when irrigation was withheld. On August 19 just before the third irrigation

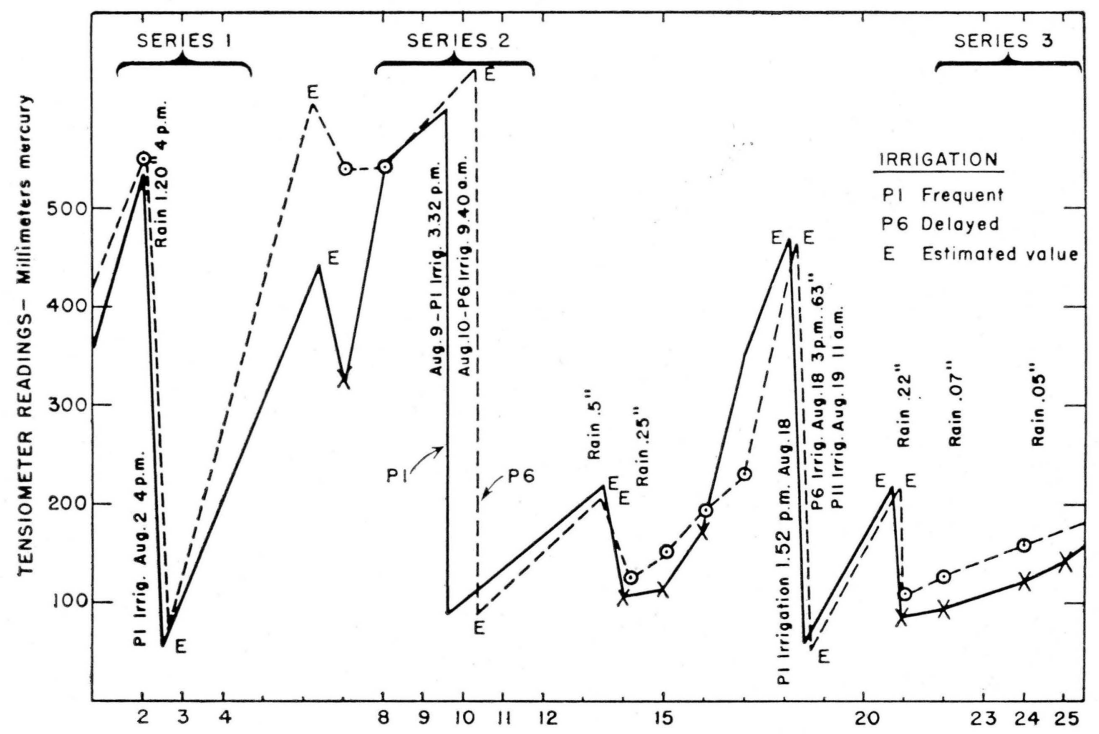

Figure 9.-Intermittent tensiometer readings (as millimeters of mercury) at a depth of 6 inches in the ridges of Progress plats (frequent irrigation, P1, and delayed irrigation, P6), at the Scotts Bluff Experiment Station in August 1951. Lacking a continuous series of readings the maxima and minima between readings, irrigations or rainfalls are estimated and indicated by $\mathbf{E}$. Symbols shown on line indicate actual readings. 
of the intermittent series (the fifth with the frequent irrigation treatments) these P11 plants had removed more soil moisture from the top 18 inches, considerably more between 18 and 30 inches, and still more at a greater depth than had the frequently irrigated plants of P1 (fig. 8).

The R.T. of the leaves of frequently irrigated plants at the Scotts Bluff Station (P1) usually attained a maximum of 95 to 98 per cent by sunrise each morning. On August 4, following a dry windy night, the maximum was only 93.2 per cent (figure 10a). During mornings when leaves were covered with dew it was not possible to be certain that the higher values of 99 to 100 per cent might not have been due to in-

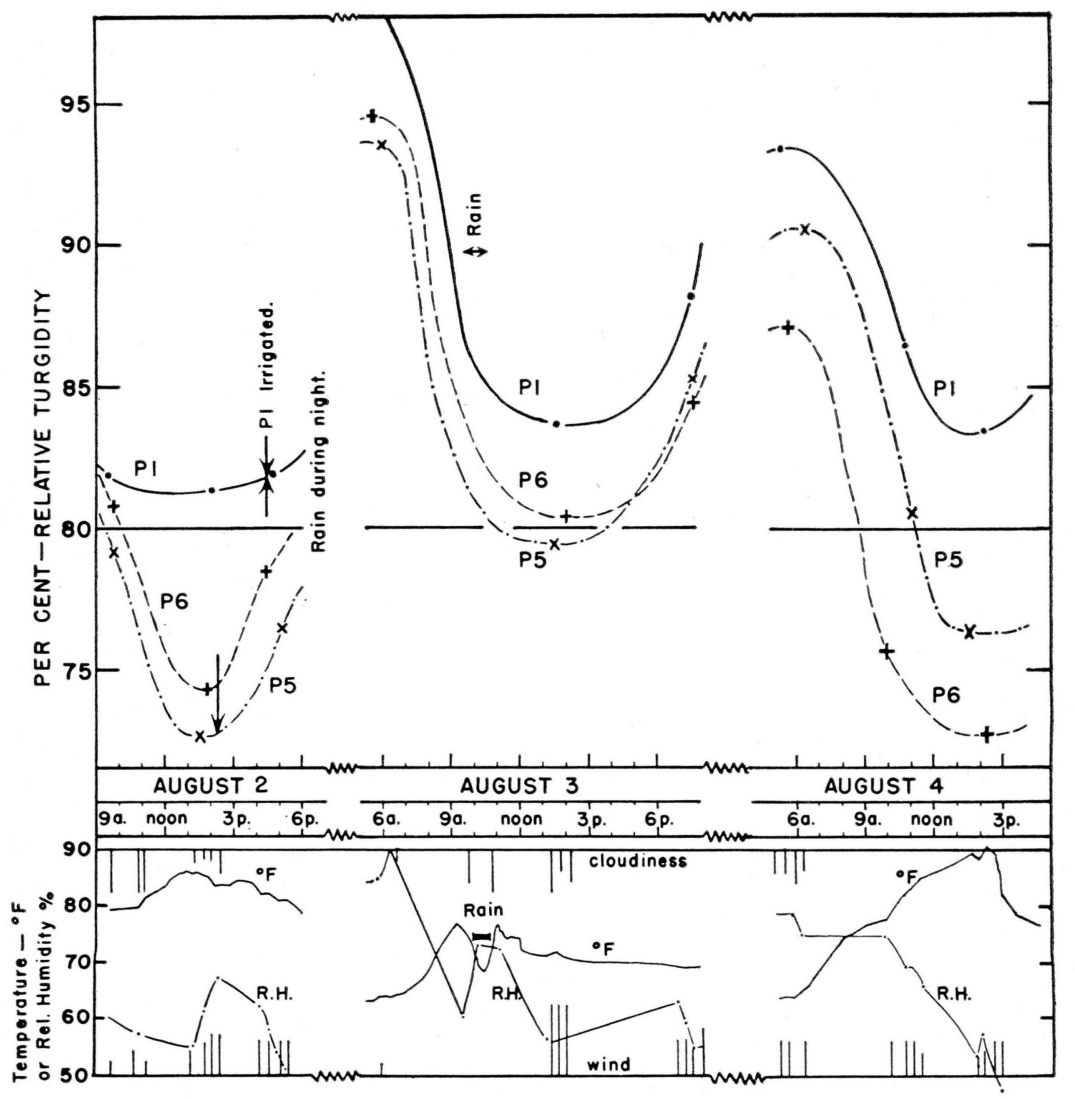

Figure 10.-Relative turgidity curves plotted from frequent samplings of Progress and Triumph plants in the three irrigation treatments and also the evaporation curve, at the Scotts Bluff Experiment Station during three groups of days in August 1951.

Part A. August 2 to 4 with Progress frequently irrigated (P1) and delayed irrigations, one of which (P5) was irrigated on August 2 and the other (P6) was continued without irrigation. 


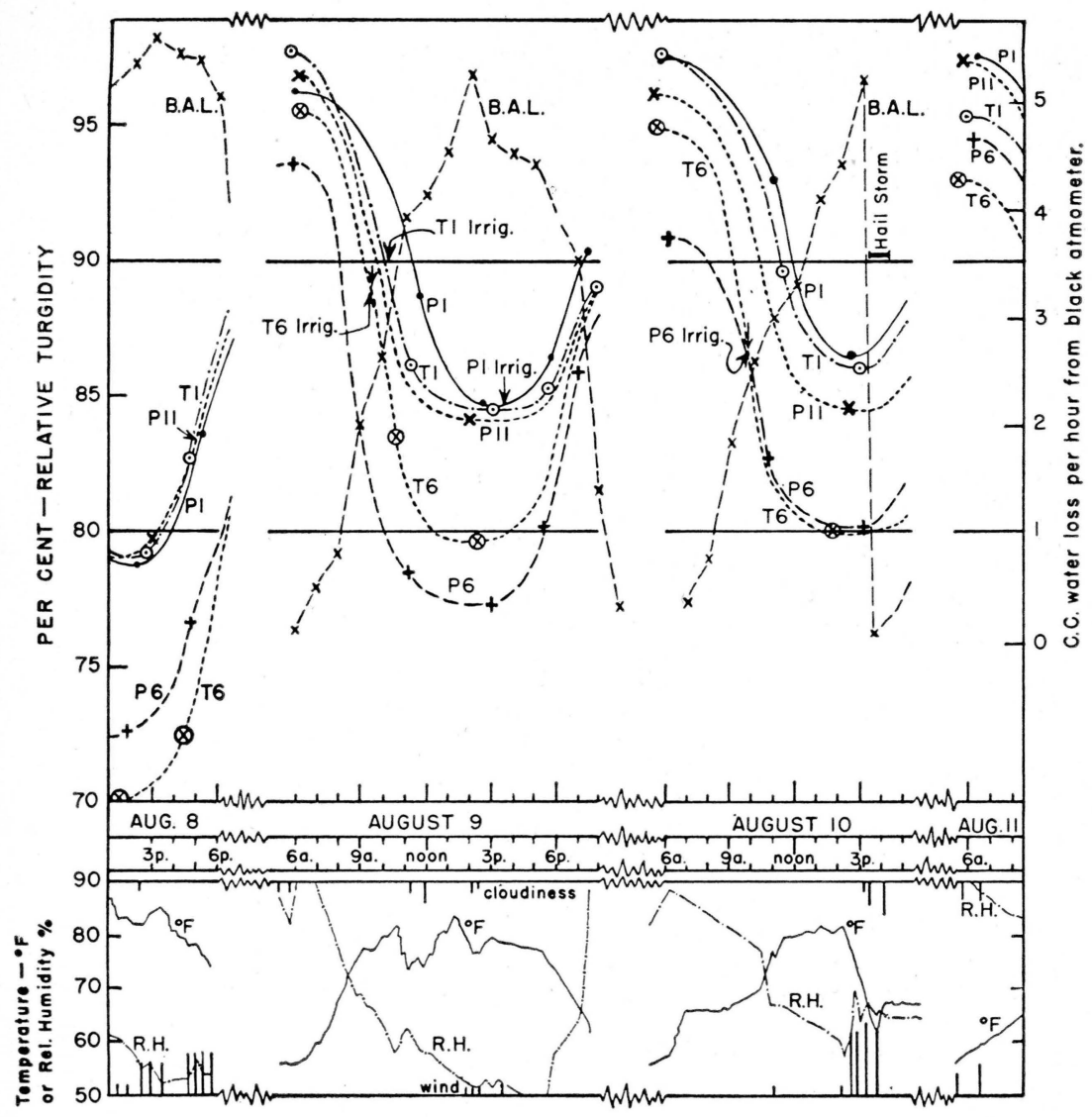

FIGURE 10.-Continued.

Part B. August 8 to 11 with frequently irrigated plats of Progress (P1) and Triumph (T1), delayed irrigation with both varieties (P6 and T6) and infrequent irrigation with Progress (P11).

ability to remove all surface moisture from disks before weighing.

Immediately after sunrise the R.T. values decreased rapidly, with a maximum rate of decrease between 7 and 10 a.m. Thereafter the rate of decrease diminished as the days advanced to minima about 3 p.m. Thereafter the R.T. values increased rapidly but not as rapidly as they had decreased during the early forenoon. The minimum values were usually between 83 and 85 per cent but sometimes they dropped to 79 per cent. This divergence in afternoon values was associated with the difference in daily range and not with the difference in morning values.

The R.T. values of leaves of the delayed irrigation plants were much lower than of those irrigated frequently (P5 or P6 vs. P1 or T6 
vs. T1) (figures $10 \mathrm{a}$ and $10 \mathrm{~b}$ ). In the early morning they were 1.5 to 6.5 per cent lower with maxima of 86 to 91 per cent. These differences increased 4 to 9 per cent during the day to day minima of 73.5 to 84.5 per cent.

Leaves of these drought-stricken plants did not seem to recover full turgidity for some time after they were irrigated. With the Progress series irrigated the afternoon of August 2 (P5) there was no indication of any effect on R.T. until after 24 hours (P5 vs. P6-August 3). Two days after water had been applied the early morning and late afternoon values were between 3 and 4 per cent higher than with the nonirrigated plants. However, they were still 4 per cent lower in the morning and 8 per cent lower in the late afternoon than the leaves of the irrigated plants (P5 vs. P1). When these plats that had been held dry for the longest time were finally irrigated the recovery of R.T. was

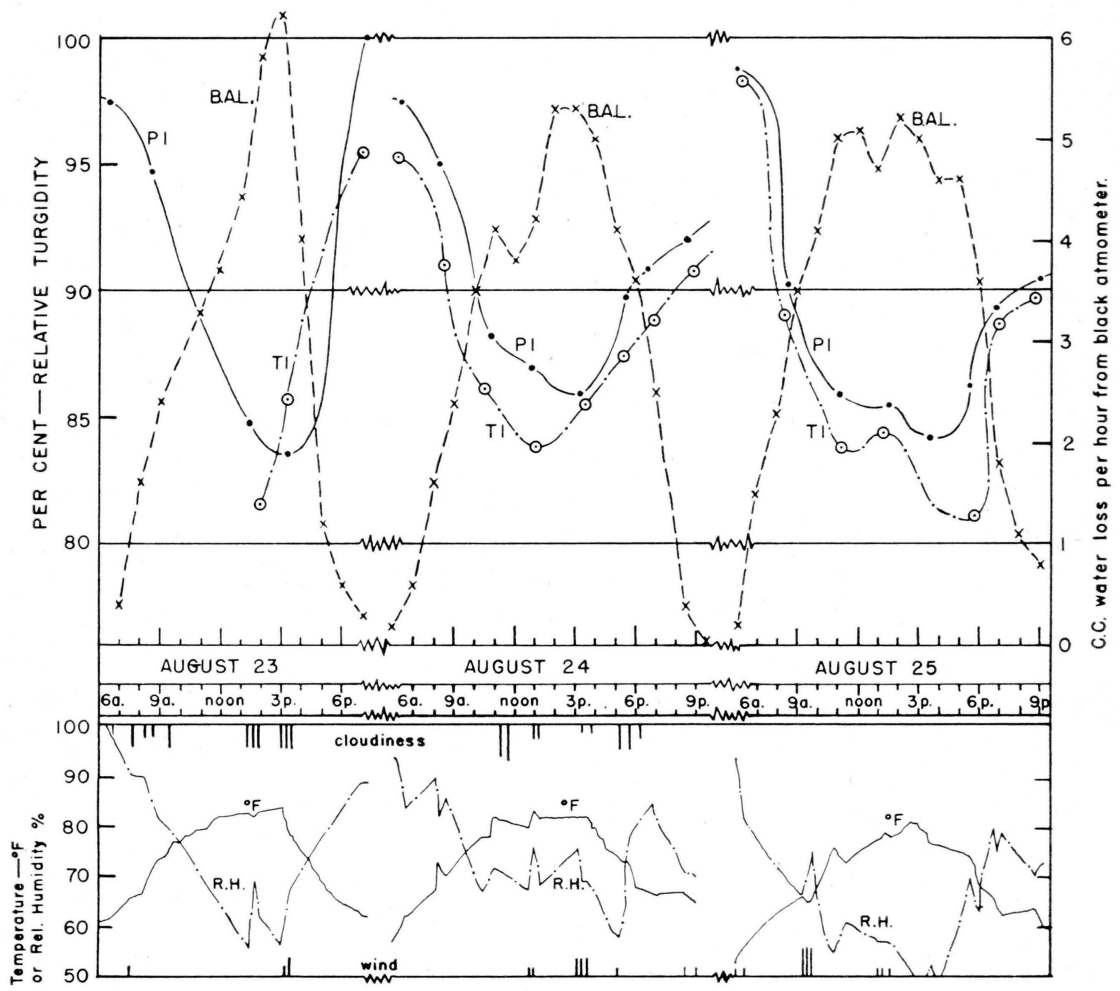

Figure 10.-Continued.

Part C. Comparison during three days, August 23-25, of the relative turgidity cycles of frequently irrigated Progress and Triumph plants (P1 and T1). 
slow. Leaves of Triumph plants irrigated the morning of August 9 showed little or no evidence of recovery by late afternoon of the 10th (T6 compared with T1 in figure 10b). Those of Progress plants irrigated the morning of the 10th (P6) may have recovered more quickly (P6 vs. P1), but with them the atmospheric situation was modified by the cool temperature and moisture accompanying a hailstorm at 3:20 p.m. on the 10th. In spite of that, on the morning of August 11 at 45 and 19 hours respectively after irrigation, the R.T. values of the delayed irrigation plants of both Triumph and Progress were still below those of the frequently irrigated plants.

With intermittent irrigation the R.T. values of Progress leaves (P11) were only slightly lower than those of the frequently irrigated plants $(\mathrm{P} 1)$ as the time arrived to irrigate the latter-on August 9 (previous irrigation of both had been on August 2) (figure 10b). Thereafter the R.T. of the irrigated plants increased still further but that of the intermittent plants that received no irrigation lagged behind. The yields of potatoes were eventually as high with this treatment (359 bushels per acre) as with those frequently irrigated (360 bushels per acre), but much higher than those with which irrigation was delayed (P6-280 bushels per acre).

The R.T. values of leaves of Triumph plants (T1) were usually lower than those of Progress by $1 / 2$ to 4 per cent in midafternoon but early in the morning there was very little difference and occasionally the values of Triumph leaves were then greater (figure $10 \mathrm{~b}$ and $10 \mathrm{c}$ ).

The nature and deviations of the daily R.T. cycle of these well irrigated plants was chiefly influenced by the vapor deficit of the atmosphere. The daily maxima-customarily occurring at or before dawn-were influenced by the wind, temperature, and relative humidity during the night. The highest values, i.e., 98 per cent or higher, occurred following nights of high humidity or very low evaporation. During many of these nights dew condensed on the plants. Following dry windy nights maximum R.T. values were as low as 92 to 93 per cent. This morning recovery was influenced by the atmospheric conditions of the preceding night and not by the extent of the R.T. depression the previous day, i.e., so long as the supply of available soil moisture in the upper root zones was maintained close to the field carrying capacity.

The daily R.T. minimum values usually attained between 2 and 3 p.m. and also the daily range in R.T. were largely determined by the accumulative vapor deficit built up each day since sunrise. The total amount of water lost from black atmometers was used as a convenient and more or less all-inclusive measure of this deficit. The rate of change in R.T. of the leaves at various times of the day was also found to be largely dependent on the vapor deficit as measured during the hour previous to sampling. The close relationship between the R.T. 


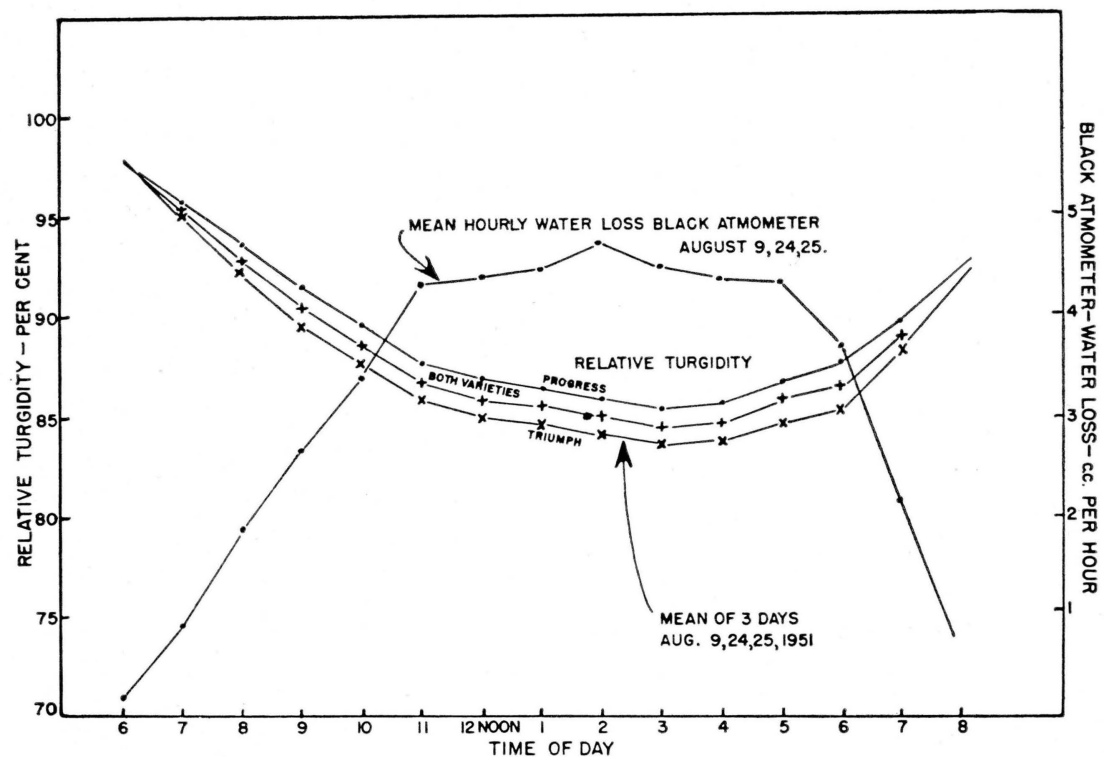

Figure 11.-Relative turgidity curves for frequently irrigated Progress and Triumph plants, based on means of values acquired in three days when readings were made at most frequent intervals and also the curves for mean hourly rate of water loss from black atmometers.

and the moisture pull of the atmosphere during the hour preceding observation is clearly shown by the mirror images of the curves for R.T. and rate of hourly water loss from the black atmometers as shown for the various days in figure $10 \mathrm{~b}$ and $10 \mathrm{c}$ and in the composite graphs of data from three days in figure 11.

When available soil moisture became deficient these daily cycles continued, but with greater daily ranges, and with both maxima and minima (especially the latter) at lower levels. These aspects are discussed more fully in another portion of this bulletin.

There was a close correlation between decreasing R.T. at any time and increasing B.A.L. during the hour preceding sampling. For 35 Progress samples at the Scotts Bluff Station, the correlation was $\mathrm{r}=$ -0.9639 . During most days the high B.A.L. rates do not occur until midday and then are likely to continue for several hours before diminishing greatly. Consequently, the morning and early forenoon high R.T. values were associated with relatively low B.A.L. values, low midday and low early afternoon R.T. values were associated with highest B.A.L. values, and intermediate late afternoon R.T. values were associated with intermediate B.A.L. values.

Viewed in another way, during the forenoon ( 6 a.m. to 11 a.m.) the regression line is relatively steep, indicating rapid decline in R.T. with increasing B.A.L. (figure 12). Part of this steep gradient in the fore- 


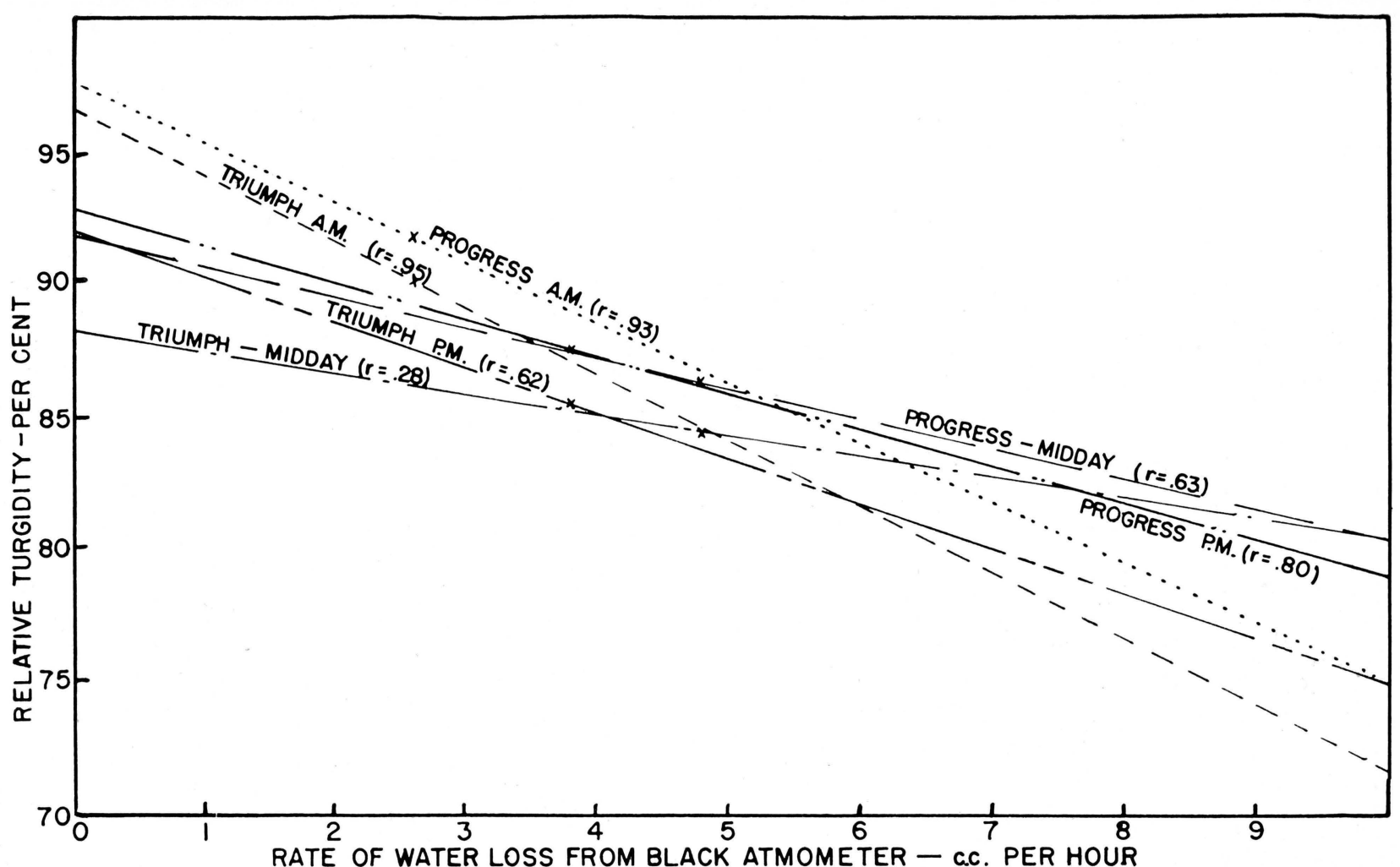

Figure 12.-Regression lines for correlation between relative turgidity of Triumph and Progress leaves in three portions of the day with vapor deficit during the previous hour measured by water loss from black atmometers at the Scotts Bluff Experiment Station in 1951 . 
noon R.T. is associated with a high B.A.L. but part is of course due to the large amount of readily transpirable water within the leaves. During midday when interior water content was low the gradient was much less as the mean rate of change in R.T. per cc. B.A.L. was relatively low. Then during late afternoon and early evening the ratio of R.T./B.A.L. values increased with a steeper gradient but still more nearly like that of midday than of the morning. This is interpreted as indicating that in spite of the great influence of accumulative internal water deficit upon R.T. at any one time, the latter was still sensitive to relatively small atmospheric changes occurring throughout the day. It is also worth noting that R.T./B.A.L. ratios were at all times higher with Progress than with Triumph leaves.

Observations at Lincoln in 1952. The plants of the six varieties used for the R.T. studies at Lincoln, June 9-19, 1952, were under distinctly xerophytic conditions during most of the observation time. Temperatures were unseasonally high during most days and there had been only .57 inch of rain since May 27. During the first three-day sampling period (June 9-11), temperatures increased each succeeding day and evaporation rates were typical of those occurring during hot midsummer days (figure 13). Consequently the plants had a xerophytic appearance, i.e., relatively small hardened leaves, but they had not

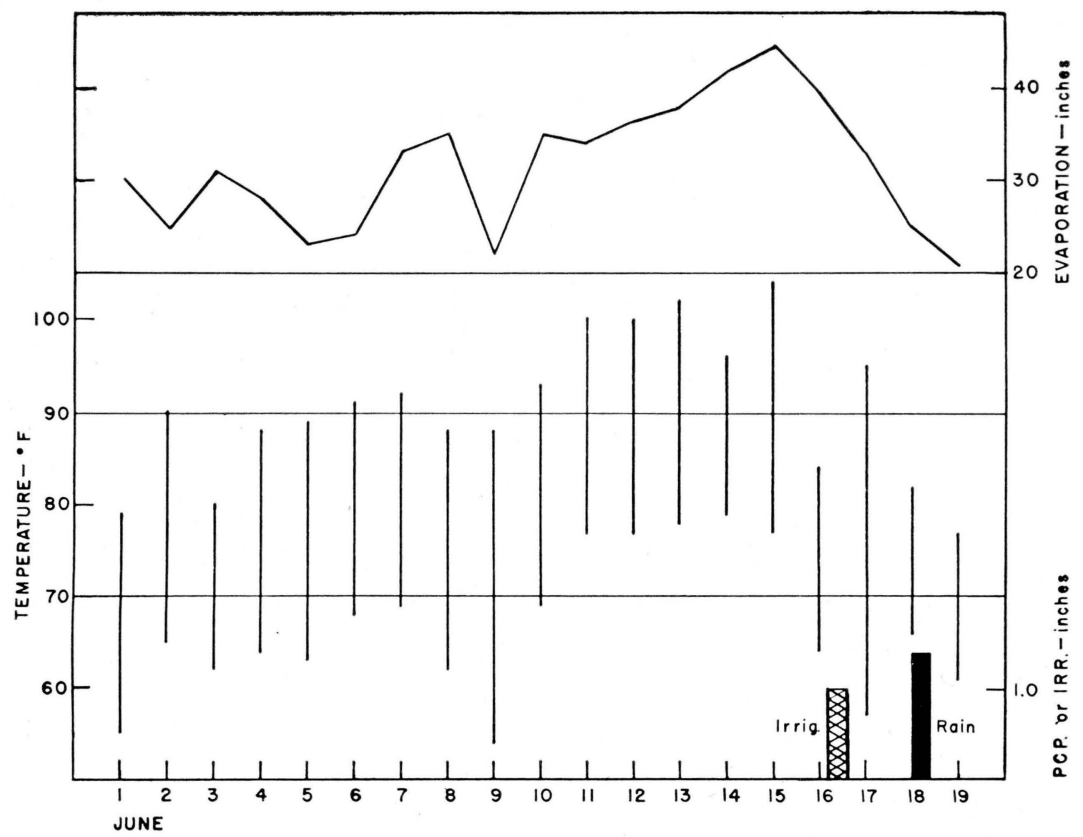

FIGURE 13.-Daily inches of evaporation, maximum and minimum temperatures, and occurrence of irrigation or rain at Lincoln during the study period in June 1952. 
yet suffered any leaf burning. During the following four days, temperatures remained very high and daily evaporation increased still more. By the close of this interval some of the leaves were drying and the new upper leaves were very small.

Throughout the second sampling period-June 16-19-temperatures were somewhat lower, daily evaporation decreased rapidly and rain occurred the night of the 17 th and throughout the 18th. This rain was preceded by an application of 1 inch of water with the overhead sprinkler system the night of the 16th, by which time leaf burning was occurring and plants were suffering much marginal burning and lower leaf dropping. Although the plants appeared to have recovered greatly by the morning of the 17 th, they again wilted severely as the midafternoon maximum of $97^{\circ} \mathrm{F}$. was approached. The rain of 1.37 inches the night of the 17th and cool and partly cloudy weather throughout the 18th provided the plants with more favorable conditions than had occurred anytime during the previous 30 days.

With these severely hardened plants the maximum and minimum R.T. values were much lower than those of the droughty plants in the more favorable cooler environment at the Scotts Bluff Station in 1951. The accumulative soil moisture deficit that was largely responsible for the low R.T. values on June 9 and 10 was increased further by the unusually high rate of evaporation on the 10th and the very high temperature and evaporation on the 11th (figures 14 and 15). Consequently, the R.T. values on June 11 were much lower, both in the morning and afternoon, and the regression lines were practically parallel with those of June 9 and 10.

During the next four very hot and unusually dry days the plants either acquired an improved water balance or responded very quickly to the slightly less severe conditions on June 16, for then the R.T. values were only slightly lower than they were on June 9 and 10 but higher than on the 11th.

A distinctly improved moisture situation was brought about with the application of 1 inch of water the evening of the 16th followed by a much lowered night temperature. Consequently, at 6 a.m. of the 17 th the R.T. values of all varieties were between 92.5 and 95.0 per cent in marked contrast to those of 83.2 to 89.5 per cent on the 16th (figure 15). However, this was a spurious or transitory recovery because by midafternoon the R.T. values were lower than those on any of the other days except June 11 (figures 14 and 15). Possibly the increased R.T. values the morning of the 17 th came about by direct absorption of water from dew on the leaf surfaces and not from a systemic increase caused by absorption by the roots.

The morning R.T. values on June 18 were again down to the low level of those of the 16th. The occurrence of these low values only 36 


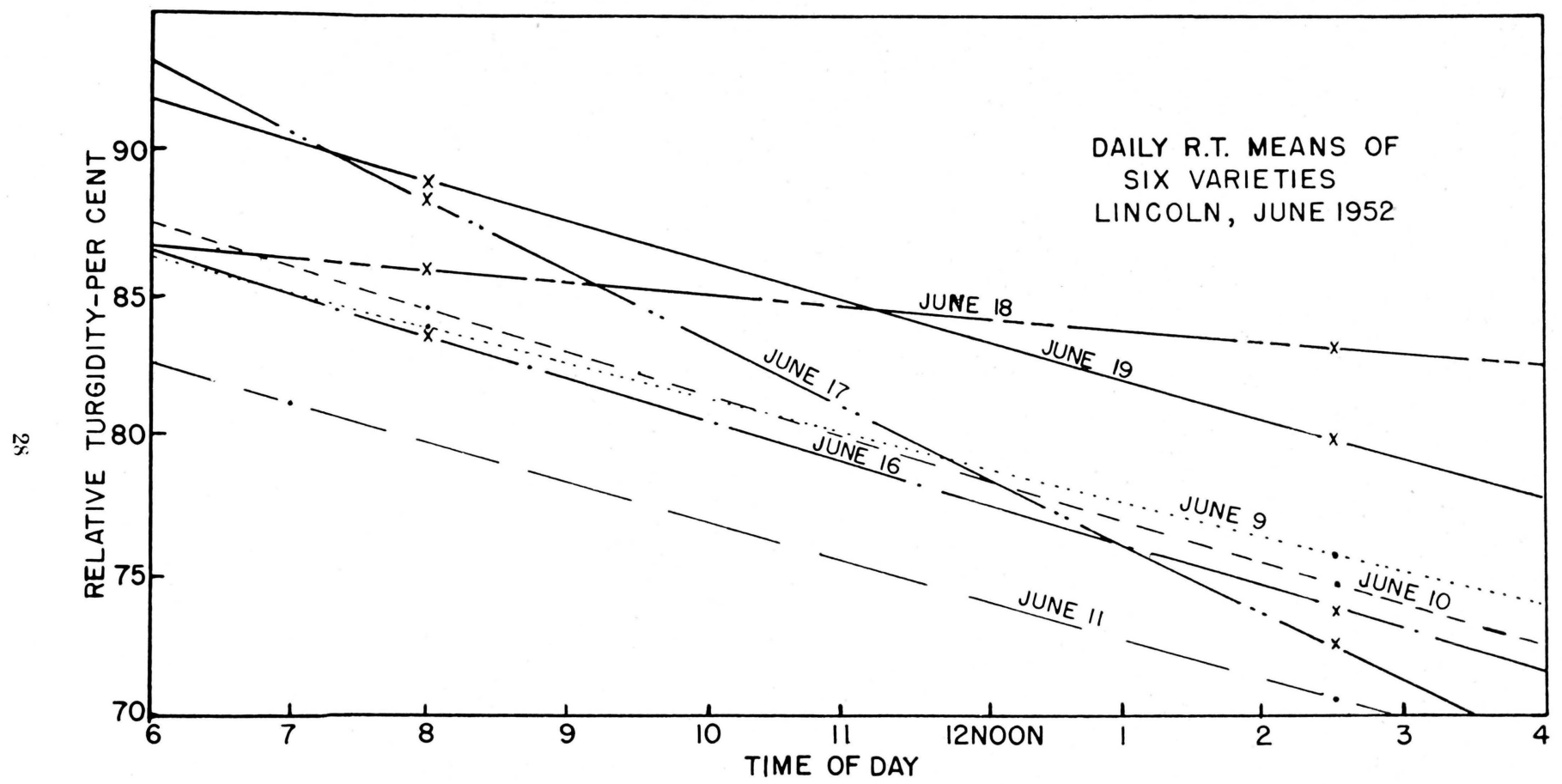

FIGURE 14.-Daily trends of decline in relative turgidity of leaves of potato plants at Lincoln in June 1952. Each line is based on means of early morning and midafternoon leaf samples of six varieties. 


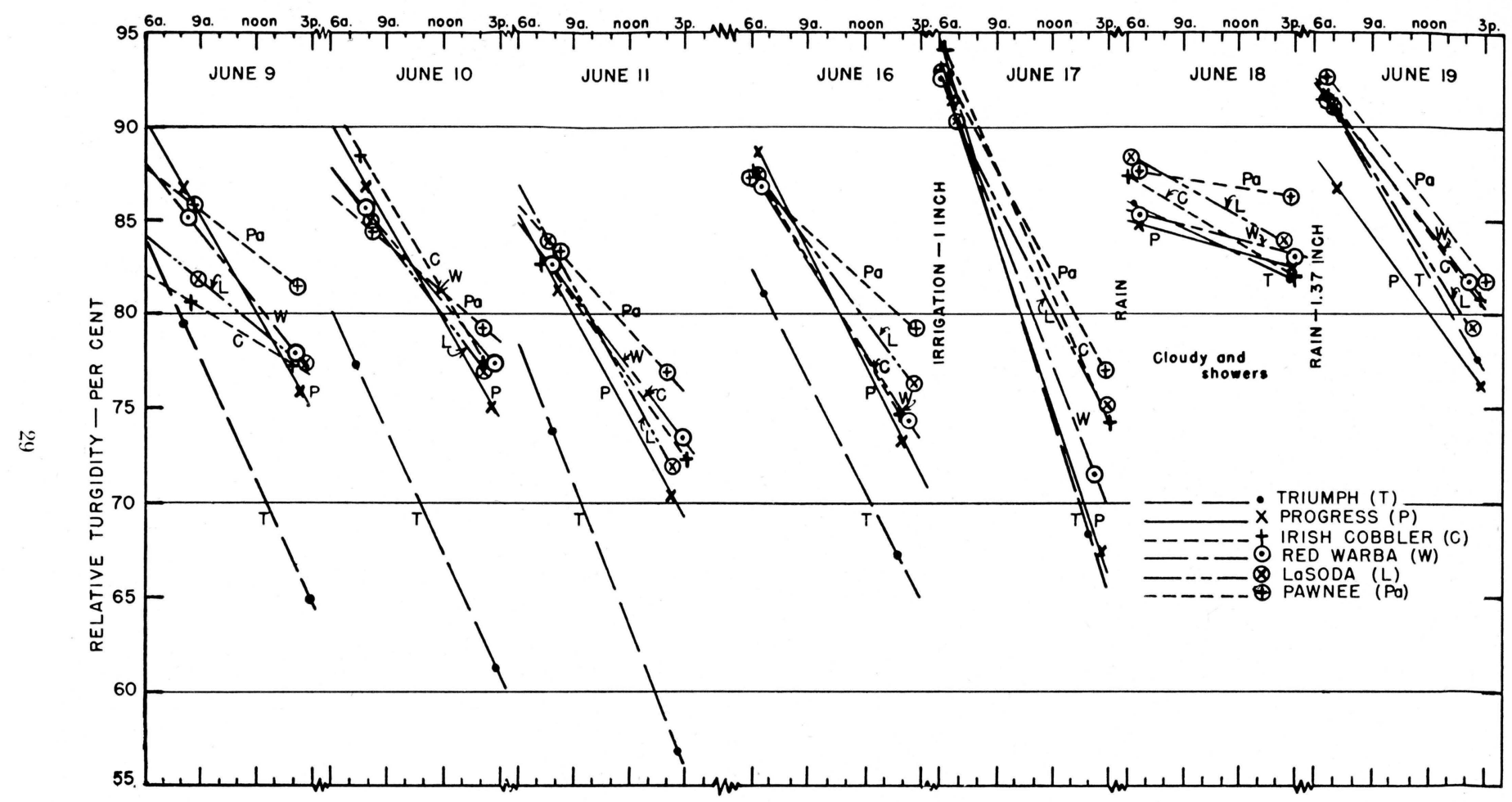

FiguRE 15.-Relative turgidity gradients for each of six varieties on each of the six days in June 1952. 


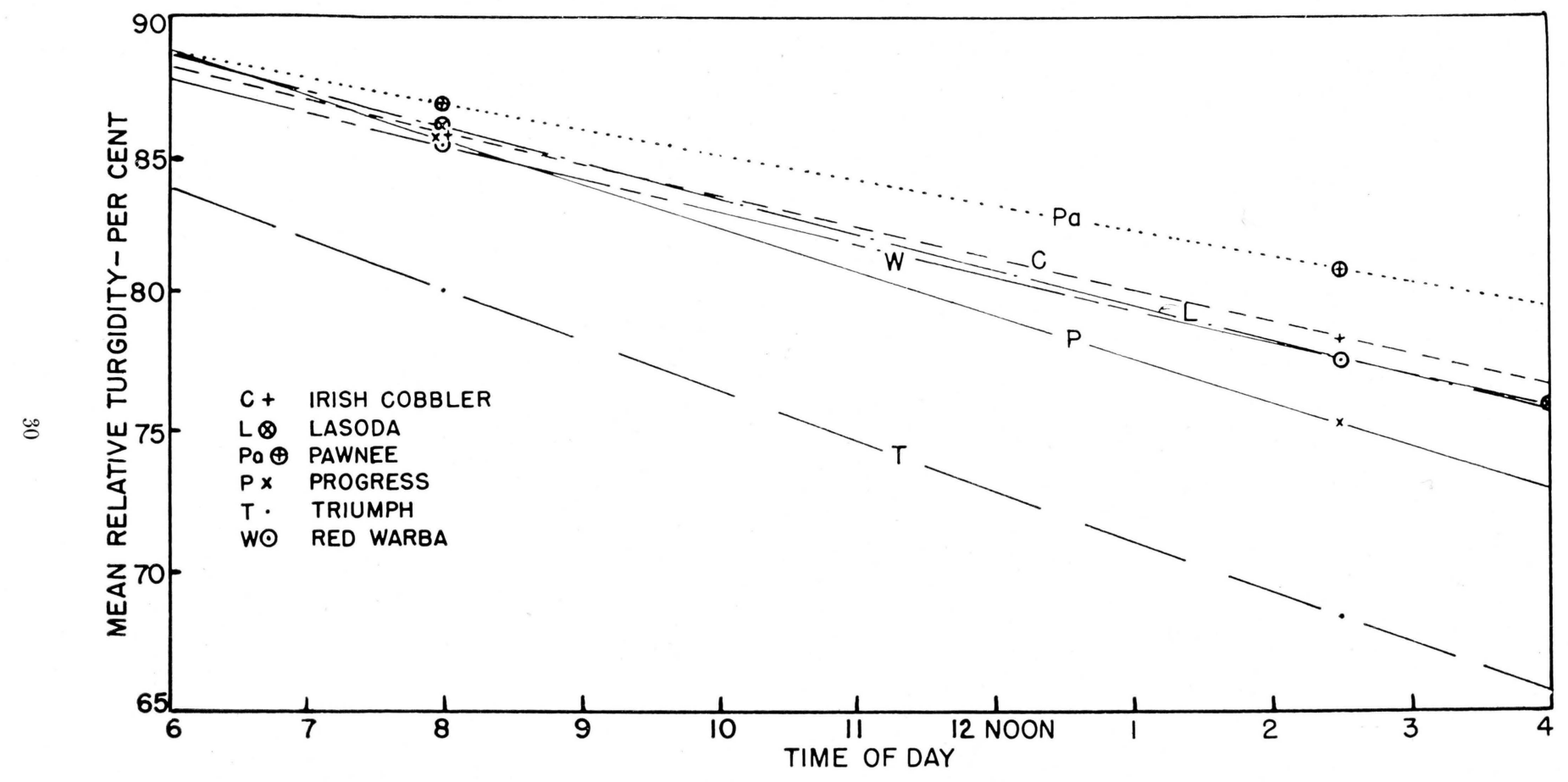

FIGURE 16.-Mean relative turgidity gradients based on six days' data with six varieties at Lincoln in June 1952. 
hours after the application of 1 inch of water may have been due to the absence or paucity of absorbing roots in the upper 6 inches of soil. Many of the roots undoubtedly died during the protracted drought of more than 30 days. The weather throughout the 18th was alternately cloudy and clear with rain falling during the early morning. Consequently, the midafternoon R.T. values were only slightly lower than at sunrise.

Following the rainfall of 1.37 inches during the late afternoon of the 18th, moisture apparently penetrated to absorbing roots for at 6 a.m. of the 19th the leaves had higher R.T. values than during any previous morning (except the $17 \mathrm{th}$ ). It appears reasonable to conclude that the moisture for these high R.T. values must have been derived from the roots, because the leaves were free of surface moisture that morning. The low evaporation of the 18th contributed further to these high values. Although the 19th was partly cloudy and relatively cool, R.T. values decreased almost as rapidly as during earlier hot, dry days-but the midafternoon values were all higher than on any day except the rainy 18 th. The resumption of high R.T. values during these two days is evidence of the ability of the leaves to regain high turgidity after prolonged drought and desiccation.

Among the six varieties, leaves of Triumph always had the lowest relative turgidity and the steepest diurnal gradient (i.e., greatest daily range), whereas those of Pawnee were highest with flattest gradients (figures 15 to 17). The difference between varieties was greater with the minimum or midday R.T. values than with the morning or maximum values. The hotter the afternoon, the greater the difference (figures 15 and 17). Although severely desiccated during the very hot days, Triumph leaves were able to regain high turgidity as well as those of any other variety when conditions became very favorable-as on the 18th and 19th.

Progress leaves reacted more nearly like those of Triumph than like those of any other variety tested. The general levels of the R. T. values of three other varieties-Red Warba, Irish Cobbler, and LaSoda-were quite similar. They were definitely lower than those of Pawnee and slightly higher than those of Progress.

The minimum midafternoon (2 to 3 p.m.) R.T. values were closely associated with the mean total amounts of water evaporated from black atmometers between sunrise and 2:30 p.m. (figure 18). The minimum afternoon R.T. values of the several varieties differed little on days when total water losses from black atmometers were below $30 \mathrm{cc}$. between about 5 a.m. and 2:30 p.m. However, as the evaporation during this period increased, R.T. values decreased much more rapidly with some varieties than with others, as shown by their regression lines (figure 18). The highest values and least reduction in R.T. occurred with Pawnee leaves followed in order by those of Irish Cobbler, La- 

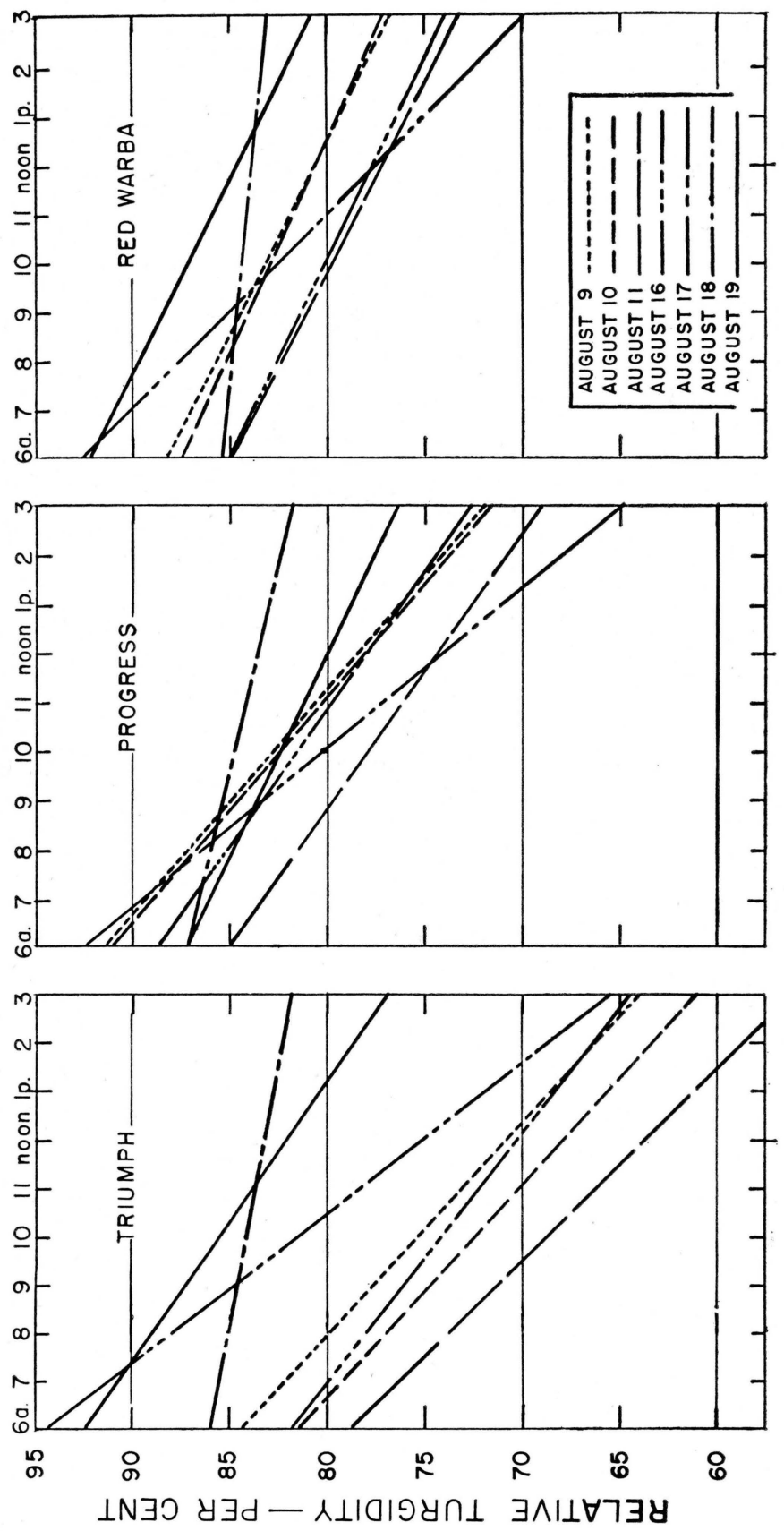

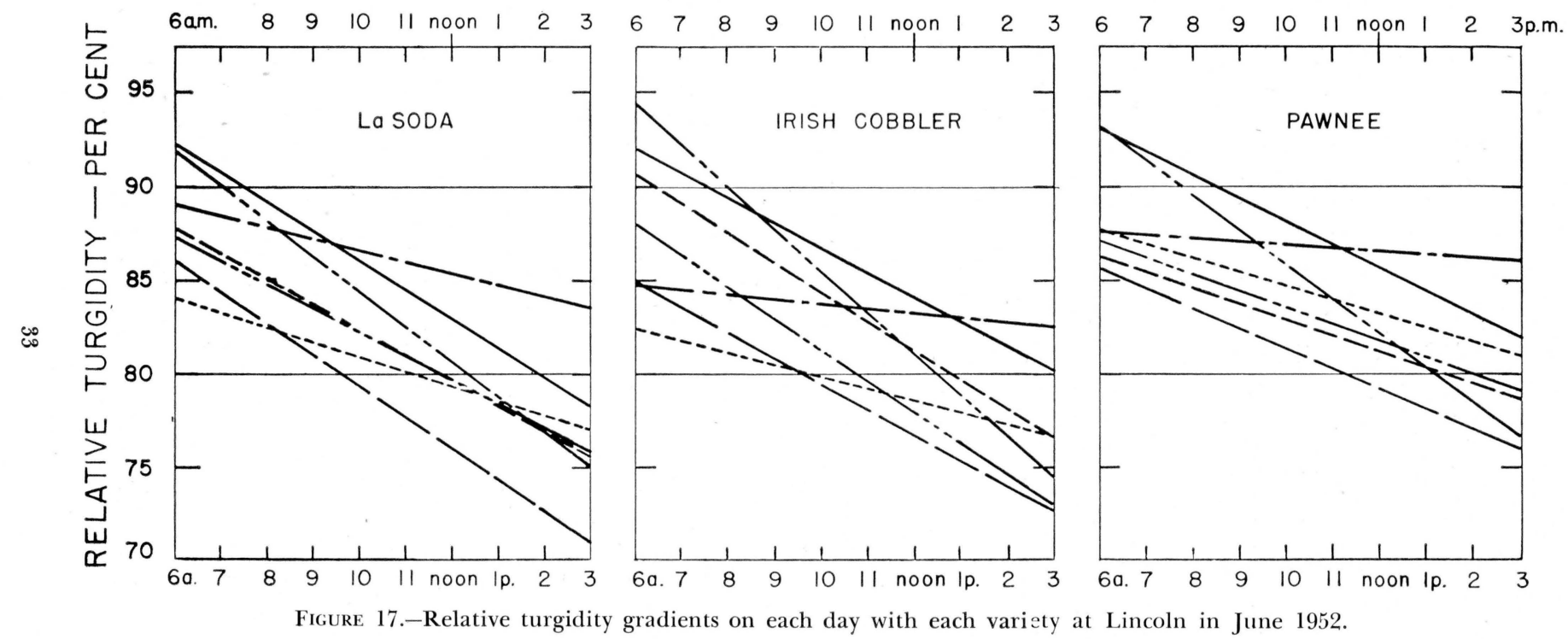

FigURE 17.-Relative turgidity gradients on each day with each variety at Lincoln in June 1952. 
Soda, Red Warba, Progress and Triumph. The regression line for Pawnee was relatively high with least gradient, whereas that of Triumph-at the other extreme-was at a much lower level with a steep gradient. The close proximity of the Pawnee and Triumph lines when evaporation was low and the great distance between them when it was high indicates their great disparity in drought and heat endurances as well as the resiliency of the Triumph plants. At this time no attempt is being made to correlate these differences in variety response to any morphological relationships. However, it may be significant that the ratios of leaf area (or weight) to stem weight are relatively low with Pawnee, increasing with the other varieties to where they are greatest with Triumph.

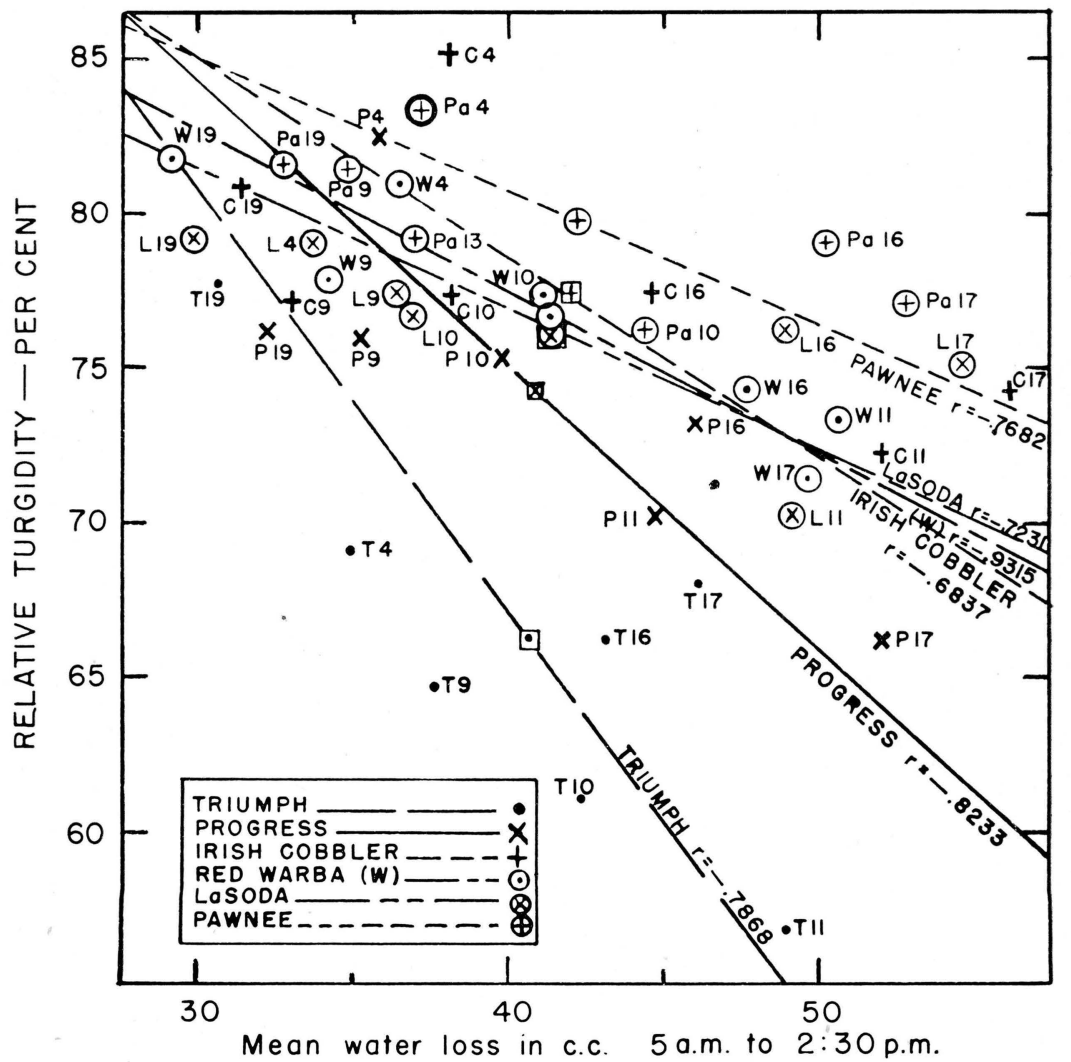

Figure 18.-Correlation between relative turgidity at 2-3 p. m. and black atmometer losses from 5 a.m. to 2-3 p.m. each of eight days with each of six varieties at Lincoln in June 1952 and regression coefficients for this interrelationship for each variety for seven days. (The data for June 18 were omitted in calculating the regression lines because, as an intermittently rainy day, the values of that day are atypical of the hot dry days under consideration.) 


\section{DISGUSSION}

The determination of relative turgidity of leaves-by a method such as was used in this study-is commended as a rapid and relatively simple method of studying the water relationships of plants as influenced by the soil moisture supply, atmospheric conditions, cultural differences, variety, etc. Further values can be visualized when considering the close relationship found by many workers between water content of leaves and photosynthetic activity of leaves (review of many pertinent papers by Miller, 1938; Crafts et al. 1949; and Kramer, 1949).

On the basis of this study it appears that even when soil moisture is relatively abundant, leaves undergo a great change in R.T. when the atmospheric vapor deficit exceeds the rate of water supply to the leaves. That this unbalance begins early in the day is shown by the fact that as the evaporating power of the air increased at an accelerated rate throughout the morning, the R.T. of the leaves decreased at a constantly diminishing rate. Then during midday when evaporation remained very high the R.T. continued low and decreased but very slowly as shown by constantly diminishing ratios of R.T./B.A.L. per hour. Finally in late afternoon and early evening the R.T. values increased much more slowly than they decreased in the morning and lagged far behind the rate of reduction in evaporation.

This suggests that as R.T. diminished in the morning, stoma closed and leaves held their water more and more tightly, and that the rate of transportation of water may have been inadequate for midday requirements, owing either to morphological limitations within the plants, to inability of roots to absorb water from the soil fast enough, or to a more or less transitory deficit in moisture in the region of the absorbing roots.

The quick response of leaves to short periods of reduced evaporation during the days, as shown by rapid increase in R.T., indicates that much of the low midday R.T. is attributable to transpiration in excess of water supply. The long midday period of high evaporation is thought to have been responsible for the very low R.T. values. During the late afternoon, recovery was fairly rapid as evaporation diminished. As time advanced into evening and night the R.T. recovery continued but at a decreasing rate. Possibly the late afternoon recovery was mostly a surge of water from the rather large supply within the transportation tissues into the then slowly transpiring leaves. Then as a balance developed there may have been a lack of water coming into the plants so that there was usually less than half as much R.T. increase in 9 hours between 9 p.m. and 6 a.m. as there had been in 4 or 5 hours prior to 9 p.m. The following morning, R.T. values were usually below 100 per cent even though there was much available water in the soil.

This might indicate that with the withdrawal of moisture from the soil at a constantly increasing rate throughout the early part of 
the day, the available moisture readily accessible to the absorbing roots was removed and either was not replaced rapidly enough from more remote portions or the roots could not grow fast enough to supply the needs of the plants. The latter hypothesis, which was offered by Weatherley, appears very useful in this situation. The inability of the plant to develop absorbing roots fast enough to keep in contact with the constantly decreasing soil moisture can explain the permanently lower level of R.T. in drought-stricken plants and also the lag of several days in recovery of full R.T. values in leaves after droughty plants were irrigated.

The significance of this root relationship is further accentuated when we realize that the leaves and stems of drought-stricken plants are much smaller than those of irrigated plants and consequently the evaporating surface is much smaller. In spite of the reduced leaf surface, the plants had lower R.T. values and they wilted earlier and for more hours each day.

A gross observation of possible value in understanding why varieties differed as much as did Triumph and Pawnee is that the former has a very large leaf/stem ratio whereas the latter has a much lower ratio.

This study indicates that R.T. determinations can be useful for ascertaining the probable comparative physiological activity of different groups of plants. The results also indicate that plants are probably functioning considerably below optimum during many hours of the day because the internal water content is much lower than their appearance indicates. The study also shows that to better understand the daily R.T. cycle it will be necessary to investigate various root relationships.

\section{SUMMARY}

1. Relative turgidity (R.T.) as determined with two sets of leaf disks cut simultaneously (one being used for determining the initial water content, the other for ascertaining the maximum turgidity of the disks after floating) was utilized to determine the daily cycle of internal moisture changes in leaves of potato varieties as affected by atmospheric and soil moisture conditions.

2. The temperature and relative humidity to which disks were exposed during floating caused variation in amount of water absorbed and consequently in the calculated R.T., but the amount or intensity of light caused little or no difference.

3. A very high negative correlation occurred between leaf appearance (as estimated by a graduated scale depicting changes from extremes of turgidity and wilting) and R.T. of leaves. The rate of change in R.T. resulting from a given change in leaf appearance differed by varieties, but with most varieties and soil moisture levels 
first visual evidence of leaf drooping occurred when the R.T. had dropped to 82-83 per cent.

4. In western Nebraska in August with the most favorable of soil moisture conditions the R.T. of leaves varied throughout the bright sunny days typical of that area from maxima of 95 to 100 per cent in early morning to minima of 82 to 86 per cent in midafternoon.

5. Morning maximum R.T. values of less than 100 per cent that occurred in leaves of plants whose roots were in soil of constantly high available moisture content were associated with the accumulative vapor deficit of the atmosphere during the previous night or even the previous day. Only during mornings following rainy nights or when leaves were wet with dew or rain was the R. T. 100 per cent or very close to it.

6. The magnitude of the daily R.T. range appeared to be influenced chiefly by the accumulative vapor deficit of the atmosphere between early morning and midafternoon. This deficit was determined in this study as the water loss from spherical black atmometers during that interval.

7. The graph of the daily cycle of R.T. values usually showed a rapid decrease in the early morning and a slow decrease during midday and early afternoon, followed by a rapid increase in late afternoon and a slower increase to a maximum during the night. It was roughly a mirror image of the graph of water loss from a spherical black atmometer.

8. The increase of R.T. during late afternoon and night lagged far behind the increase in the vapor content of the atmosphere. This was evidence of an internal (systemic) moisture deficiency or transitory moisture deficiency in the micro-root environment.

9. As available soil moisture diminished to the point where the top 18 inches was at or close to the wilting point and only half of the available moisture at 18-30 inches remained, both the maximum and minimum daily R.T. values decreased and the daily range in R.T. increased.

10. During the last days of a protracted rainless period of very high temperatures at Lincoln in June 1952, R.T. values were 7 to 10 per cent lower than in the more moderate weather at the Scotts Bluff Experiment Station. Under these conditions maximum morning values were never over 90 per cent (usually 85-90 per cent), except in the mornings after sprinkler irrigation or rain, when values were between 90 and 95 per cent. During the hot weather the midafternoon minima were usually below 78 per cent, the extent of their depression having been correlated with B.A.L. (cc. water black atmometer loss) since 5 a.m.

11. The R.T. values of varieties differed relatively little when soil moisture was readily available, but when it became deficient there were 
small differences in maximum morning values and large differences in the minimum midafternoon values. At the close of the protracted hot, dry period differences between varieties were very great. Those of Triumph were lower and the daily range much greater, whereas those of Pawnee were higher and the daily range smaller than those of other varieties.

12. Although drought-stricken plants gave the appearance of quick recovery when irrigated, the recovery of high turgidity so as to equal that of plants continually well supplied with water was a slow process requiring several days of favorable environment. 


\section{BIBLIOGRAPHY}

Crafts, A. S., H. B. Currier and C. R. Stocking, Water in the Physiology of Plants, (especially chapters VIII to X), Chronica Botanica Co., Boston, 1949.

Kramer, Paul J., Plant Physiology, McGraw-Hill Book Co., New York, 1949.

Miller, Edwin C., Plant Physiology, pp. 598-600, 2nd Ed., McGrawHill Book Co., New York, 1938.

Stone, Winona E., "Normal Growth of Potato Leaves in Greenhouse and Field," Journal of Agricultural Research 46:565-578, 1933.

Weatherley, P. E., "Studies in the Water Relations of the Cotton Plant.

"I. The Field Measurements of Water Deficits in Leaves," New Phytologist, 49 (1) pp. 81-97, March 1950.

"II. Diurnal and Seasonal Changes in Relative Turgidity and Environmental Factors," New Phytologist, 50 (1) pp. 36-51, May 1951. 
